\title{
Onset and End of the Rainy Season in the Brazilian Amazon Basin
}

\author{
Jose A. MARengo \\ Centro de Previsão de Tempo e Estudos Climaticos, INPE, Sao Paulo, Brazil \\ BRANT LIEBMANN \\ Climate Diagnostics Center, University of Colorado, Boulder, Colorado \\ VERNON E. KOUSKY \\ Climate Prediction Center, NCEP/NWS/NOAA, Washington, D.C. \\ NAZiano P. FiLIzola \\ Agencia Nacional de Aguas e Energia Electrica, Brasilia, Brazil \\ ILANA C. WAINER \\ Departamento de Oceanografia Fisica, Instituto de Oceanografia, Universidade de Sao Paulo, \\ Sao Paulo, Brazil
}

(Manuscript received 21 June 1999, in final form 27 March 2000)

\begin{abstract}
Onset and end of the rainy season in the Amazon Basin are examined for the period 1979-96. The onset and end dates are determined by averaging daily rainfall data from many stations, and then constructing 5-day averages (pentads). Onset (end) is defined as the pentad in which rainfall exceeds (falls below) a given threshold, provided that average rainfall was well below (above) the threshold for several pentads preceding onset (end), and well above (below) the threshold for several pentads after onset (end). For the criteria chosen, the climatological onset progresses toward the southeast, arriving in mid-October, and then toward the mouth of the Amazon, arriving near the end of the year. The end dates are earliest in the southeast and progress toward the north, but withdrawal is slower than onset. The onset dates, however, are quite sensitive to changes in the threshold. If the threshold is doubled, for example, the sense of onset is reversed, with onset occurring toward the northwest. Changes in threshold do not change the direction of the progression of the end of the rainy season.

The central Amazon shows the largest variation in the date of onset. In several years, onset in the southeast occurs before that in the central Amazon, but onset near the mouth is always latest. There is an unexpectedly low relationship between the length of the rainy season and total accumulation. Likewise, there is little relationship between the onset (and end) date and the total accumulation.

Composites of outgoing longwave radiation and the low-level wind field show that in the central Amazon, onset is associated with an anomalous anticyclone and enhanced trade winds in the Atlantic. Near the mouth of the Amazon, however, onset is associated with large-scale northerly anomalies, and the zonal component of the trade winds is reduced.

There is an apparent association between sea surface temperature anomalies in the tropical Atlantic and Pacific and the pentads of onset and end of the rainy season in the northern and central Amazon, and near its mouth. The sense is that a warm Pacific and cold Atlantic result in a delayed onset and early withdrawal. Although the strong El Niño of 1982/83 and La Niña 1988/89 were examples of a delayed and early onset, respectively, the relationships it still holds these years are not considered.
\end{abstract}

\section{Introduction}

An understanding of the interannual variability of rainfall in the Amazon Basin is of interest because of

Corresponding author address: Dr. Jose A. Marengo, CPTEC/ INPE, Cachocira Paulista, São Paulo, Brazil.

E-mail: marengo@cptec.inpe.br its importance to agriculture, hydroelectricity production, transportation, and to the general circulation and global hydrological cycle. Most studies of interannual variability of Amazon rainfall have concentrated on its association with the El Niño-Southern Oscillation (ENSO). During the "warm" phase of ENSO, associated with El Niño, there is often a deficit of precipitation in northern and central Amazonia (e.g., Aceituno 1988; 
Rogers 1988; Ropelewski and Halpert 1987, 1989; Kiladis and Diaz 1989; Rao and Hada 1990; Marengo 1992; Rao et al. 1996; Marengo et al. 1998; Uvo 1998).

Other studies have implicated the Atlantic, at least indirectly, as being responsible for interannual rainfall variability in the Amazon. For example, Marengo (1992) found above-average rainfall throughout the basin in southern summer during seasons with enhanced northeast trades, due to increased moisture flux from the Atlantic. Rao et al. (1996) also showed that Amazon convection is controlled partly by moisture transport from the Atlantic. Strong Atlantic trades bringing anomalous moisture into the Amazon are associated with a southward displaced intertropical convergence zone (ITCZ), which is in turn related to an anomalous distribution of Atlantic sea surface temperature (SST) anomalies (Hastenrath and Heller 1977; Moura and Shukla 1981; Nobre and Shukla 1996). Modeling studies by Lau and Nath (1994) and Lau (1997), however, suggest that the changes of tropical Atlantic SST during El Niño years are forced by, rather than the cause of, changes in atmospheric circulation. Therefore both are ultimately driven by changes in Pacific SST.

In a monsoon environment such as that of the Amazon Basin (Zhou and Lau 1998), the dates of the onset and end of the rainy season determine its length, and variations in the length of the rainy season are likely to be related to the interannual variability of total rainfall during the rainy season. Therefore a better understanding of the causes of onset and of the rainy season may improve our understanding of interannual variability. Another reason for studying the onset of the rainy season is that for some agricultural applications, an accurate prediction of the date of onset would be more useful than a good prediction of total rainfall.

A variety of methods have been used to identify and predict the onset of the rainy season in the tropical monsoon regions of the world. Troup (1961), Ramage (1971), Murakami and Sumi (1982), and Holland (1986) proposed wind-based definitions, while Troup (1961), Virmani (1975), and Nicholls et al. (1982) used definitions depending on amount or accumulation. Davidson et al. $(1983,1984)$ noted that the summer monsoon during First Global Atmospheric Research Program (GARP) Global Experiment was characterized by periods of active tropical convection on a very large scale and so defined monsoon onset as the first flare-up of tropical convection over northern Australia. Hendon and Liebmann (1990) used the low-level wind-based definition of Holland, modified to include rainfall, which also was used by Joseph et al. (1991) to study the interannual variability of the Australian monsoon onset and how it is influenced by the Indian summer monsoon, El Niño, and SST.

There have been relatively few efforts devoted to understanding onset in the Amazon Basin. Kousky (1988) determined the climatological onset date at every point on a $2.5^{\circ}$ grid using satellite-based outgoing longwave radiation (OLR) measurements. He defined onset as occurring when climatological OLR fell below $240 \mathrm{~W} \mathrm{~m}^{-2}$ in a given 5-day average (pentad), provided that 10 of the 12 previous pentads had OLR above $240 \mathrm{~W} \mathrm{~m}^{-2}$ and 10 of the 12 subsequent pentads had OLR below $240 \mathrm{~W} \mathrm{~m}^{-2}$. He determined that, generally, onset progresses from northwest to southeast, although his criteria were never met in the extreme northwest, because values were almost always below the $240 \mathrm{~W} \mathrm{~m}^{-2}$ threshold. Withdrawal of the rainy season occurs toward the northwest. The results of Sugahara (1991), who used a combined index of OLR and rainfall, were consistent with those of Kousky (1988).

Horel et al. (1989), also using pentads of OLR, defined a quantity "fractional longwave radiance" (FLR) as the number of grid points within a $10^{\circ} \times 10^{\circ}$ box, which have OLR values less than $240 \mathrm{~W} \mathrm{~m}^{-2}$, divided by the number of grid points in that box. They defined onset (end) of the rainy season in the summer hemisphere of the tropical Americas as the first pentad of a period in which the maximum FLR remains within (outside) that hemisphere for at least 25 days. Although the seasonal cycle was shown to be much larger than interannual variability in the Amazon, they did find yearto-year variations of more than a month in both onset and end of the rainy season. This study showed that the Bolivian high is established soon after the onset of convection, implying that it is a response to latent heat release over Amazonia. Studies by Rao and Erdogan (1989), Lenters and Cook (1995), and Garreaud (1999) show that the atmospheric heat source over most of the Bolivian Altiplano is dominated by the contribution of latent heat. This explains the episodic and convective nature of rainfall over the Altiplano associated with uplifting of moist air from the lowlands to the east of the Andes.

More recently, Zhou and Lau (1998) showed the evolution of the circulation near South America for one austral summer, with emphasis on the features associated with onset and demise of the rainy season. They concluded that in view of the similarities with other monsoon regions, South America does support a true monsoon.

$\mathrm{Fu}$ et al. (1999) showed that prior to onset in the Amazon, there is a systematic buildup of planetary boundary layer (PBL) moisture. The atmosphere in the southern Amazon is quite stable; therefore large surface heating is required to force the transition to the rainy season. Near the equator, however, stability during the dry season is weaker. Therefore, they conclude, onset is more sensitive to small changes in the dynamic and thermodynamic structure relative to the southern Amazon, and onset is likely to be influenced by adjacent SSTs. Their results also suggest that the onset of the rainy season in regions such as central Amazonia and the mouth of the Amazon River may be also influenced by other factors, such as land surface forcing.

The purpose of the work presented here is to docu- 


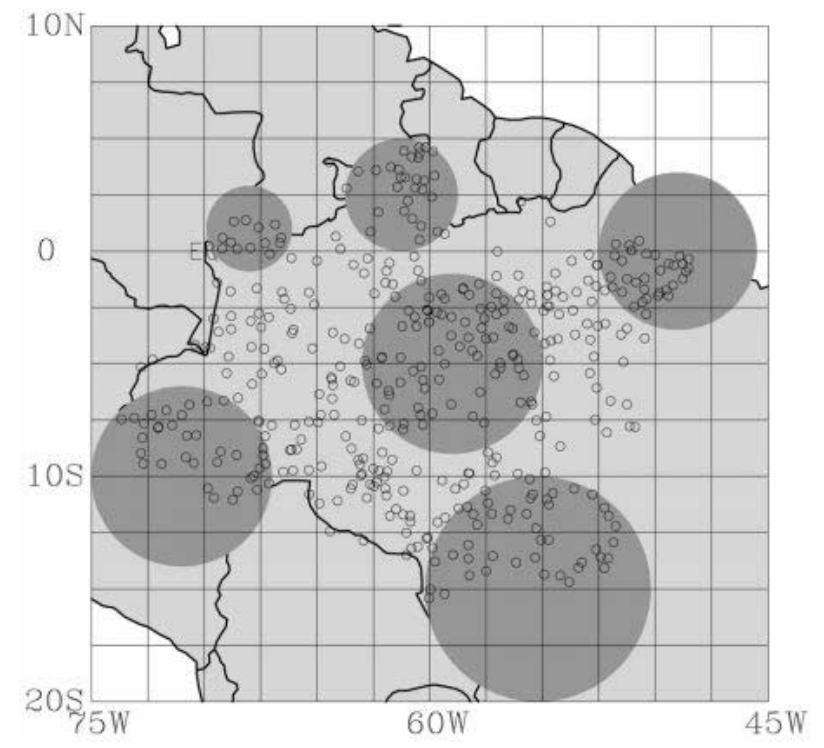

FIG. 1. Location of rainfall stations used in this study (open circles), and regions within which averages are made for further analysis (shaded circles).

ment the interannual variability of the onset and end of the rainy season in the Brazilian Amazon Basin, to show their relation to interannual variability of seasonal and annual precipitation, to show the evolution of the circulation in relation to the onset and end of the rainy season, and to determine if the onset of the rainy season is related to an external influence (i.e., SST anomalies). The availability of data from a large number of stations allows a regional focus. It is hoped that this will contribute to a better understanding of the causes of interannual variability of rainfall within the Amazon Basin.

\section{Data}

\section{a. Rainfall}

The National Water and Electric Energy Agency of Brazil has made rainfall data from many stations available. After eliminating obviously erroneous data, we use data from 429 stations whose records contain at least 4 yr of data between 1979 and 1997, with no more than $33 \%$ missing during the years with data. On average, included stations contain $12 \mathrm{yr}$ of data, with $11.8 \%$ of the reports during those years listed as missing. The locations of the stations are shown in Fig. 1.

Five-day averages (pentads) were computed for each of the 73 pentads for each year. A $2.5^{\circ}$ gridded pentad climatology is constructed by averaging all available data for a pentad if the station is located within $1.8^{\circ}$ of a given grid point. Thus a few stations may be included in adjacent grid boxes, which acts as a weak spatial smoother. We also construct pentad series for six different regions (shown in Fig. 1 and discussed below) by averaging all available data for a given pentad.

\section{b. NCEP and ECMWF reanalysis fields and OLR}

Global, gridded wind fields were obtained from the U.S. National Centers for Environmental PredictionNational Center for Atmospheric Research (NCEPNCAR) reanalysis (Kalnay et al. 1996). The model was run at total wavenumber 64 (T64), then interpolated to pressure surfaces at T35 resolution. The present study utilizes pentad averages at $850 \mathrm{hPa}$ made from fourtimes-daily fields, interpolating the evenly spaced gridded fields to a Gaussian grid, and then applying a spectral transform determined streamfunction. From 1979 to 1992, the Australian surface pressure bogus data was inadvertently shifted prior to assimilation by $180^{\circ}$ of longitude. Problems associated with this error are believed to be confined to south of $40^{\circ} \mathrm{S}$ and are most severe during winter (e.g., Garreaud and Wallace 1998).

The ECMWF upper-air analyses at $2.5^{\circ}$ lat $\times 2.5^{\circ}$ long spatial resolution were acquired for the year 1980 93 (Palmer et al. 1992). Trenberth and Olson (1988), Palmer et al. (1992), and others have considered the quality of the European Centre for Medium-Range Weather Forecasts (ECMWF) reanalysis. A limited comparison with the NCEP-NCAR reanalysis indicates that major characteristics of the large-scale circulation are reliably captured.

Monthly mean SST fields (on a Gaussian $192 \times 94$ grid) are taken from the reanalysis "skin" temperature. Over the ocean, these temperatures are equivalent to Reynolds reconstructed SST (Reynolds and Smith 1994). Pentad averages of OLR are also formed. Prior to averaging into pentads, missing values have been replaced by interpolation, primarily in time (Liebmann and Smith 1996).

\section{Results}

\section{a. Climatological features}

Previous work by Figueroa and Nobre (1990), Marengo (1992), Rao et al. (1996), Hastenrath (1997), and Zhou and Lau (1999, manuscript submitted to J. Climate) among others have documented the annual variation and the spatial regime of rainfall in Brazil and tropical South America. In most of the Brazilian Amazon, there is a large annual cycle of precipitation, with the largest amounts falling in austral summer. In southern Amazonia, the peak of the rainy season is from January to April, and the dry season is from June to August. Near the mouth of the Amazon, almost $60 \%$ of the annual totals fall from March to May. In the northwest and central Amazon, rainfall is relatively evenly distributed over the year. The northwest and mouth of the Amazon have the largest annual total precipitation amounts. The links between the seasonal distribution of rainfall with those of large-scale circulation and convection have been discussed extensively in previous studies (Horel et al. 1989; Hastenrath 1997; Garreaud 
and Wallace 1998). Overall, the convection over the Amazon Basin prevails in austral summer.

Times series of the pentad climatology for rainfall within each of the six regions highlighted shown in Fig. 1 are shown in Fig. 2. Also shown are the corresponding series of OLR. The OLR series were computed by calculating the climatology at the closest Gaussian grid point truncated at T30. A T30 truncation is consistent with using stations averaged within a radius of about $3^{\circ}$ (Liebmann et al. 1998).

OLR climatology is useful for monitoring interannual variability and for providing an overall view of the distribution of deep tropical convection, throughout the year. OLR, however, gives only a rough approximation of the beginning and ending dates of the tropical rainy season, and does not always adequately represent precipitation. Near Manaus (central Amazonia), it was observed that the annual cycle of OLR does not match that of rainfall (Liebmann et al. 1998). Marengo (1995) used the deep convective clouds (DCC) products from the International Satellite Cloud Climatology Project (ISCCP) and found that both OLR and DCC products can capture the annual cycle of precipitation as shown by rain gauges, even though the maximum of OLR/DCC can be somewhat out of phase with those of rainfall, especially in the cloudy regions of northwest Amazonia.

Figure 2a shows the series for the northwest. Even the climatology is relatively noisy, owing in part to the small number of stations that are included in the average (see Table 2). Consistent with other studies, abundant rainfall is observed in this region all year long. The pentad climatology never dips below $6 \mathrm{~mm}$ day $^{-1}$. Rainfall does not correspond well to OLR. According to OLR there are two annual maximums in convection, near the end of April and in mid-October, but just the former is observed in rainfall, and it occurs a month later than that in OLR.

In contrast to the northwest, there is a distinct rainy season in the northern Amazon (Fig. 2b). Near the beginning of April, rainfall jumps dramatically from about 2 to almost $8 \mathrm{~mm}$ per day over about 4 pentads. It remains elevated until around mid-August, after which it drops slightly less rapidly than the rate of increase during April. Again, OLR does not correspond well to rainfall. The peak in OLR is too early by about a month, and there is an indication of a secondary maximum near the beginning of November, which is not evident in rainfall.

Although the areas referred to as the north and northwest Amazonia are both located within the Amazon Basin, they are north of the equator. The rainfall maxima correspond to the annual movement of convection from the Southern into the Northern Hemisphere (e.g., Horel et al. 1989).

The central Amazon (Fig. 2c) exhibits a much longer rainy season than in the north (Fig. 2b), but there is also a contrast between the wet and dry seasons. Even during the driest part of the year, on average in July, average rainfall exceeds $2 \mathrm{~mm} \mathrm{day}^{-1}$. The phasing of OLR, particularly during the dry season, is consistent with that of rainfall.

Of the six regions shown here, rainfall is heaviest during the wet season near the mouth of the Amazon. There is an abrupt onset near the end of December, with rainfall exceeding $10 \mathrm{~mm}$ day $^{-1}$ from early January until mid-May. OLR displays quite high values during the dry season. Rainfall, however, never dips much below $2 \mathrm{~mm} \mathrm{day}^{-1}$.

Rainfall during the southeast dry season, which is centered in early July, is nearly absent (Fig. 2e). At the peak of the wet season, however, rainfall is heavier than in the central Amazon (Fig. 2c). The southeast is in marked contrast to the southwest (Fig. 2f), at which rainfall during the rainy season is only two-thirds that of the southeast, yet the dry season is less severe in the southwest than the southeast.

It is interesting to contrast the relationship between rainfall and OLR in the different regions. For example, although the wet season is wetter in the southeast than in the southwest, OLR in the southwest is lower than in the southeast. The discrepancy probably results from the higher elevation in the southwest compared to the southeast. The contrast in other regions is equally apparent. It is likely that at least part of the varying relationship between OLR and rainfall is due to a mismatch of exact locations and scales between the two quantities. These discrepancies do illustrate the advantages of using measurements of rainfall when examining regional and smaller-scale features.

\section{1) ONSET AND END}

From the climatologies shown in Fig. 2, it is apparent that the transition from dry to wet season occurs when rainfall, which is averaging less than $3 \mathrm{~mm}$ per day, jumps abruptly to at least $6 \mathrm{~mm} \mathrm{day}{ }^{-1}$. The reverse is observed at the end of the rainy season. Therefore, the onset (end) date of the rainy season is defined from rainfall data as that pentad with daily average precipitation greater (less) than $4 \mathrm{~mm} \mathrm{day}{ }^{-1}$, provided that 6 of the 8 preceding (subsequent) pentads had precipitation of less than $3.5 \mathrm{~mm} \mathrm{day}^{-1}$, and 6 of the 8 subsequent (preceding) pentads had precipitation of greater (less) than $4.5 \mathrm{~mm} \mathrm{day}{ }^{-1}$. The criteria for the preceding and subsequent pentads are included because rainfall is a fairly noisy quantity, and we want to ensure that we are capturing the true transition.

The dates of onset and end of the rainy season in Amazonia based on the gridded pentad climatology are shown in Fig. 3. Although in the northwest the $4 \mathrm{~mm}$ day $^{-1}$ criterion is almost always exceeded, so no onset is defined, onset dates progress southeastward from near mid-September in the north and west to the beginning of October in the southeast. Near the mouth of the Amazon, onset occurs almost at the end of December, while north of the equator, rainfall is apparently tied to North- 

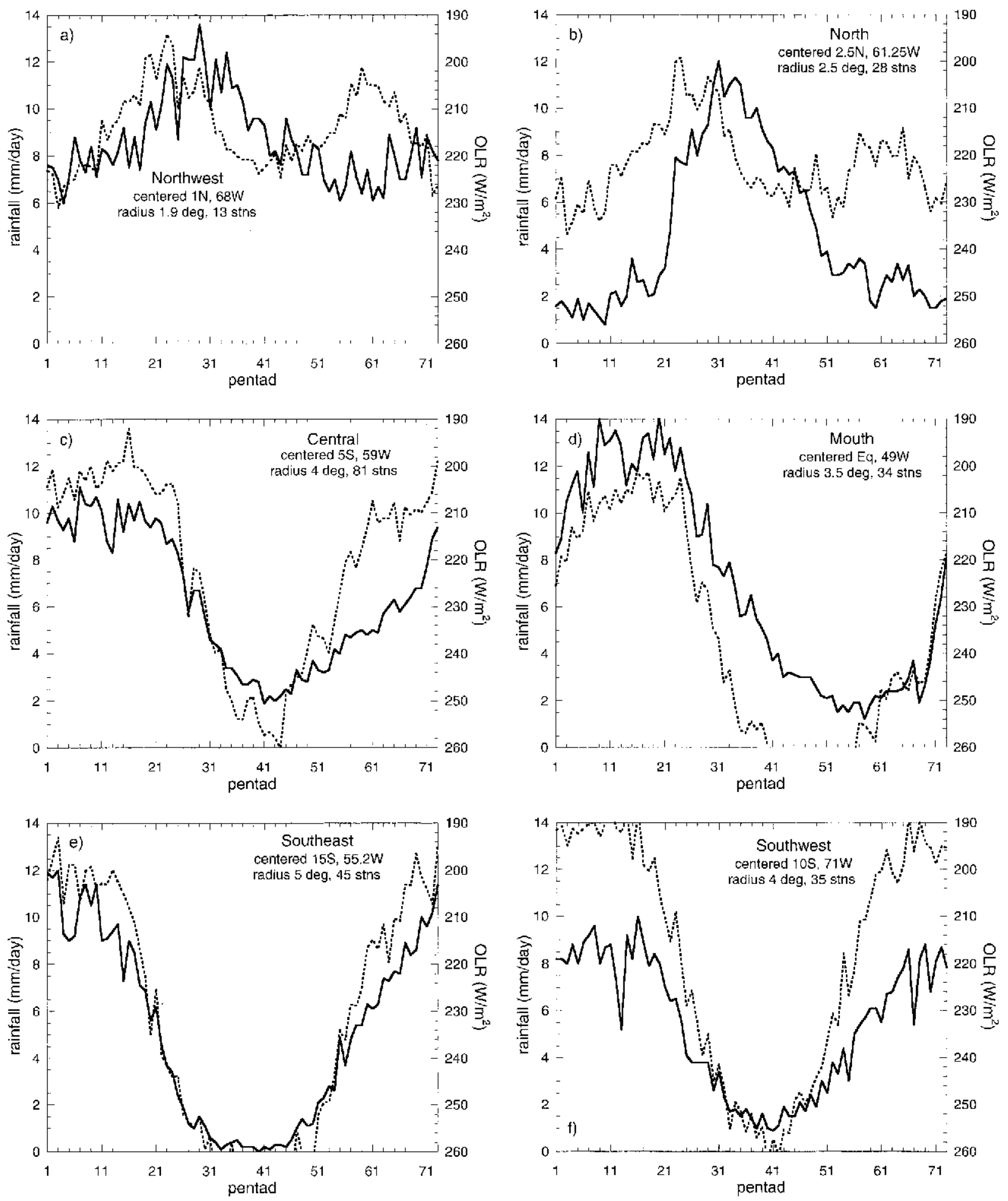

FIG. 2. Time series of the pentad climatology of rainfall (solid) and OLR (dotted) for each of the six regions shown in Fig. 1. The center of the circle within which rainfall is averaged, its radius, and the number of stations included are shown in each panel. OLR is taken from the Gaussian grid point nearest the center of the circle and truncated at T30. 


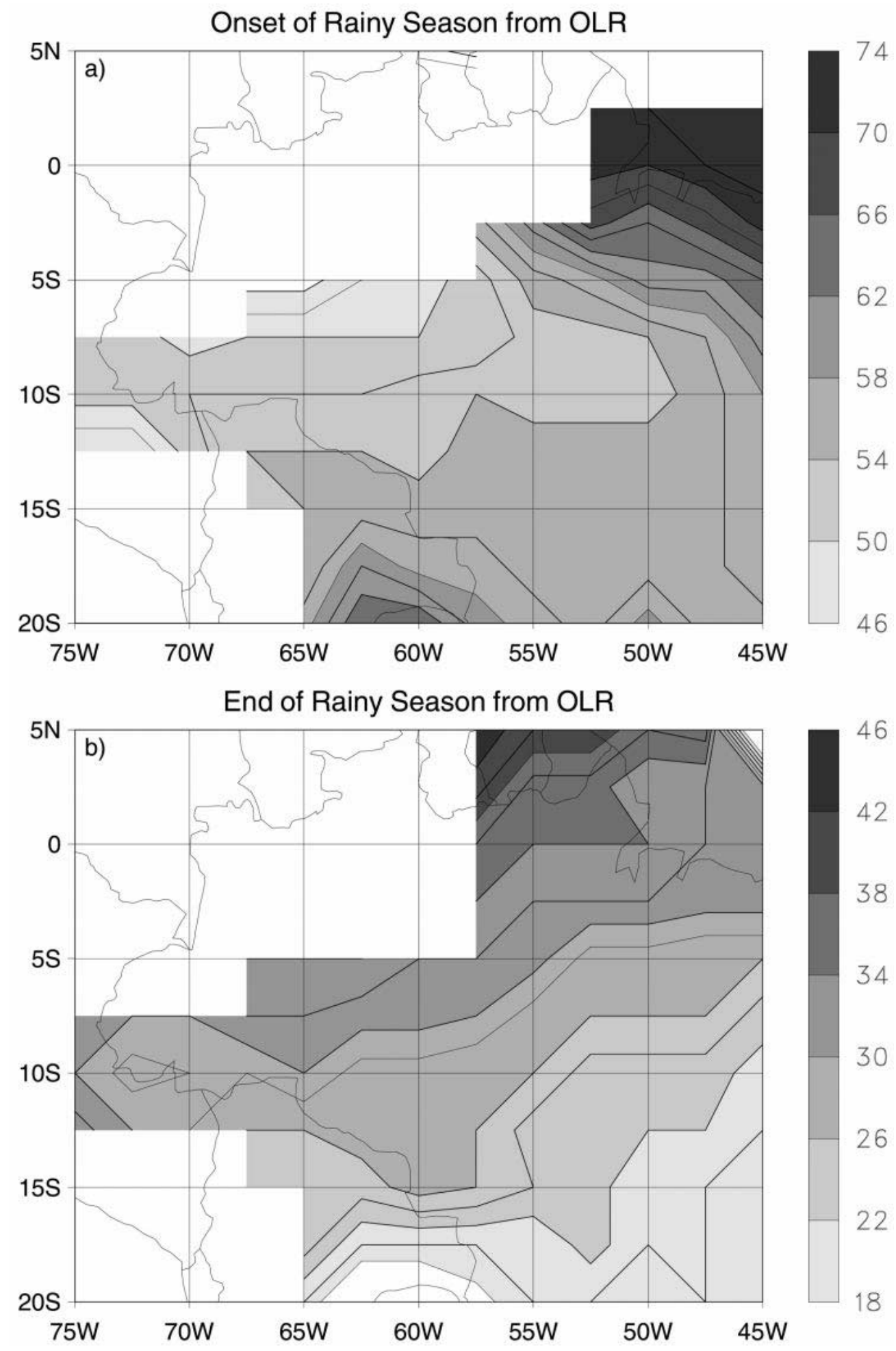

FIG. 3. (a) Onset and (b) end dates of the rainy season in Amazonia, for the period 1979-97, based on pentad climatology of gridded rainfall. Numbers represent pentad of onset. Shading starts on (a) pentad 46 (centered on 16 Aug), and (b) pentad 18 (29 Mar) with an interval of 4 pentads. Darker shades represent later dates. Contours are at intervals of 2 pentads. In blank areas, criteria for onset or end were not met. 
ern Hemisphere summer and does not occur until midApril.

The withdrawal of the rainy season progresses toward the north, but moves slower and more systematically than does onset, consistent with the findings of Horel et al. (1989). The withdrawal begins in the southeast in mid-April, close to the time of onset in northern Amazonia. The shortest rainy season is in the southwest, while in the northwest rainfall is more or less continuous.

For comparison, the climatological onset and end of the rainy season for OLR is shown in Fig. 4, using the same definition as that employed by Kousky (1988). There is a reasonable qualitative agreement, with onset progressing rapidly to the southeast and withdrawing more slowly to the northwest. Again, the latest onset dates are near the mouth. In general, onset/end occur earlier/later with the definitions based on OLR.

If the climatological onset and end dates are averaged over the Amazon Basin [South American sector $\left(5^{\circ} \mathrm{N}-\right.$ $\left.\left.15^{\circ} \mathrm{S}, 50^{\circ}-72.5^{\circ} \mathrm{W}\right)\right]$, the average onset date is the pentad centered on 25 September, while the average ending date is the pentad centered on 2 June. Thus, the present definition of onset and end using rainfall data give a substantially longer rainy season than that determined by Horel et al. (1989), who found that deep convection shifts from the northern into the Southern Hemisphere in mid-October and returns to the Northern Hemisphere in early April.

\section{2) SENSITIVITy TO THRESHOLD CRITERIA}

Since the transition between wet and dry seasons are most distinct in the southeast Amazon, the area in which onset and end are defined shrinks toward the southeast as the threshold criteria are decreased. The dates are sensitive to the criteria; each millimeter decrease results in an approximate 20-day lengthening at each end of the rainy season (Figs. 5a-1).

As the threshold rainfall criteria are increased, the onset and end dates become defined in northwest Amazon. The change in onset date per millimeter is larger in the north than it is to the south, so that when the threshold is at $8 \mathrm{~mm} \mathrm{day}^{-1}$ (Figs. $5 \mathrm{~g}$ and $5 \mathrm{~h}$ ), the rainy season appears to begin near the beginning of December in the southeast and progress rapidly to the northwest, arriving there near the end of December. This is the result of a gradual increase in rainfall rates during the rainy season in the northwest (Figs. 5c-f) as compared to a more rapid increase in the southeast. Even using the $8 \mathrm{~mm}$ per day criterion, the end dates still progress from southeast to northwest. The number of grid points meeting the criteria decrease at higher levels (Figs. 5i-1).

\section{3) Composites OF CiRCUlation AND OLR}

In order to illustrate circulation changes associated with onset of the rainy season in different parts of Ama- zonia, we show composite maps of the difference between the average of 4 pentads after onset minus the 4 pentads before onset. The pentad of onset is not included. Composites of low-level wind from the NCEPNCAR and ECMWF reanalyses, as well as the OLR fields, are shown. The composites using ECMWF data include one less year than do those using the NCEPNCAR reanalysis, as the ECMWF reanalysis ended in 1993.

Onset of the rainy season in the central Amazon is associated with an increased anticyclonic circulation in eastern Amazon (Figs. 6c, 7c), with an increase in northerly flow over the base region. Although the composite OLR after onset is lowest in the central Amazon (Figs. $6 \mathrm{~b}, 7 \mathrm{~b})$, the larger decrease in OLR occurs to the east. There is a decrease in OLR over Central America and the Caribbean.

The anomalous anticyclonic flow is farther south for onset in the southeast (which occurs on average just one pentad later than that in central Amazon). The Atlantic trade winds are also stronger after onset (Figs. 8a, 8b, $9 \mathrm{a}, 9 \mathrm{~b})$. Southeast onset appears to be associated with an extension of low OLR values from the north rather than a basinwide decrease in OLR.

Onset near the mouth of the Amazon displays distinctly different characteristics than the composites from the interior (Figs. 10a, 10b, 11a, 11b). In this case there appears to be a large-scale increase in low-level winds from the north, and the zonal component of the trade winds actually decreases. There is a dramatic decrease in OLR near the mouth, with an extension of low values into the Atlantic associated with a southward expansion of the ITCZ. The composite fields shown in Figs. 6-11 computed from both the NCEP-NCAR and ECMWF reanalyses for central Amazonia, southeast Amazonia, and the mouth of the Amazon indicate that the circulation composites are insensitive to the reanalysis scheme.

\section{b. Interannual variability}

Figures $12 \mathrm{a}-\mathrm{e}$ show the variability of the rainy season (pentad of onset and end for each year for each of the regions except the northwest). The variation of onset date is clearly largest in the central Amazon. Even though the average onset date in the central Amazon is earlier than in the other regions (south of the equator), in individual years onset often occurs later than onset in the southwest or southeast, but always earlier than near the mouth of the Amazon. For the ending dates, the progression of the end of the rainy season is much more uniform than that of onset, mainly due to the decrease in the variability of the ending date compared to the onset date in central Amazon. The end in central Amazon occurs always after the end in either the southwest or southeast, and almost always before the end near the mouth.

Less variability in the onset and demise dates is ob- 


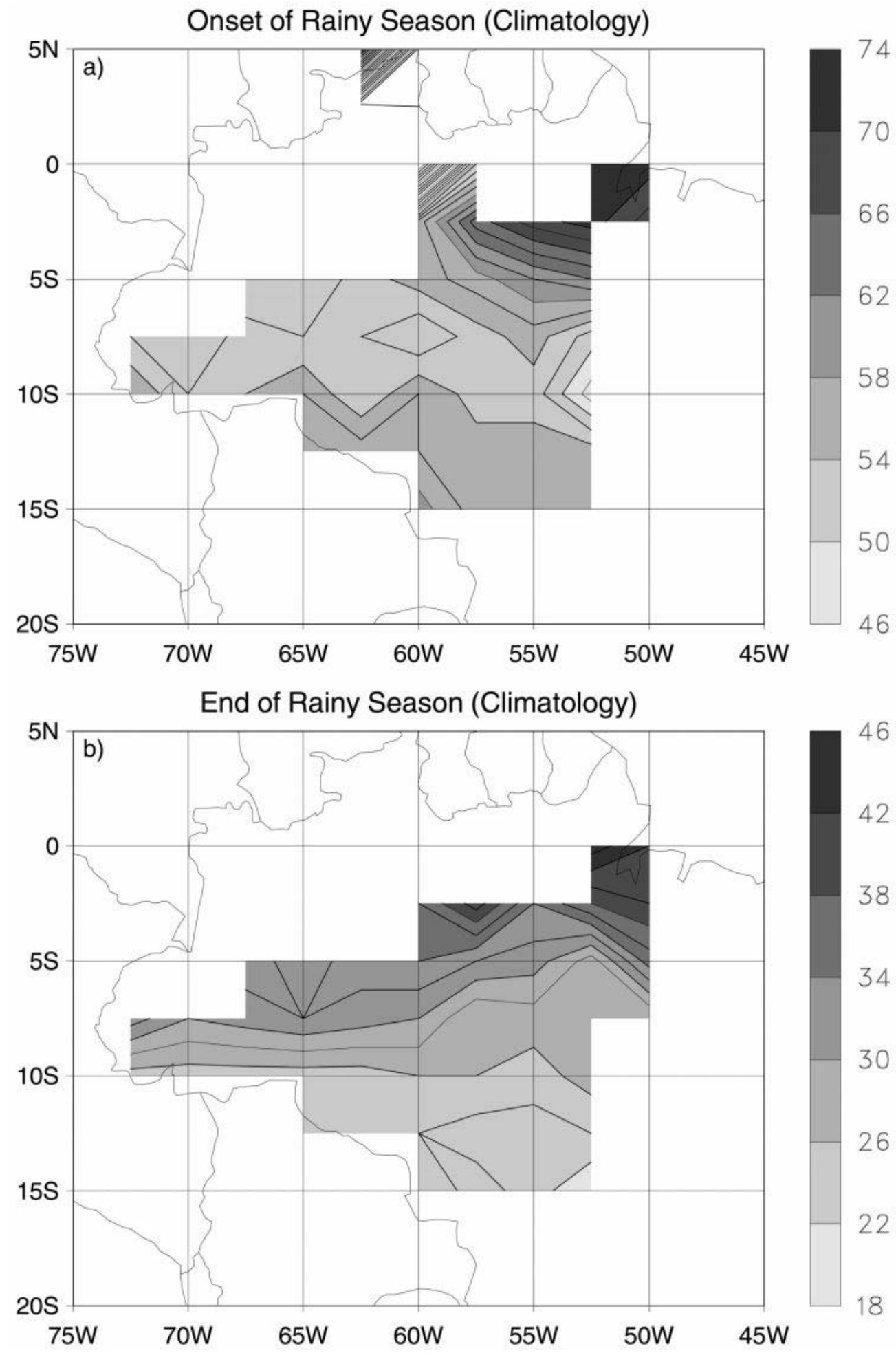

FIG. 4. As in Fig. 3 except onset and end defined based on OLR. Definitions of onset and end are those used by Kousky (1988) and are defined in the text. 

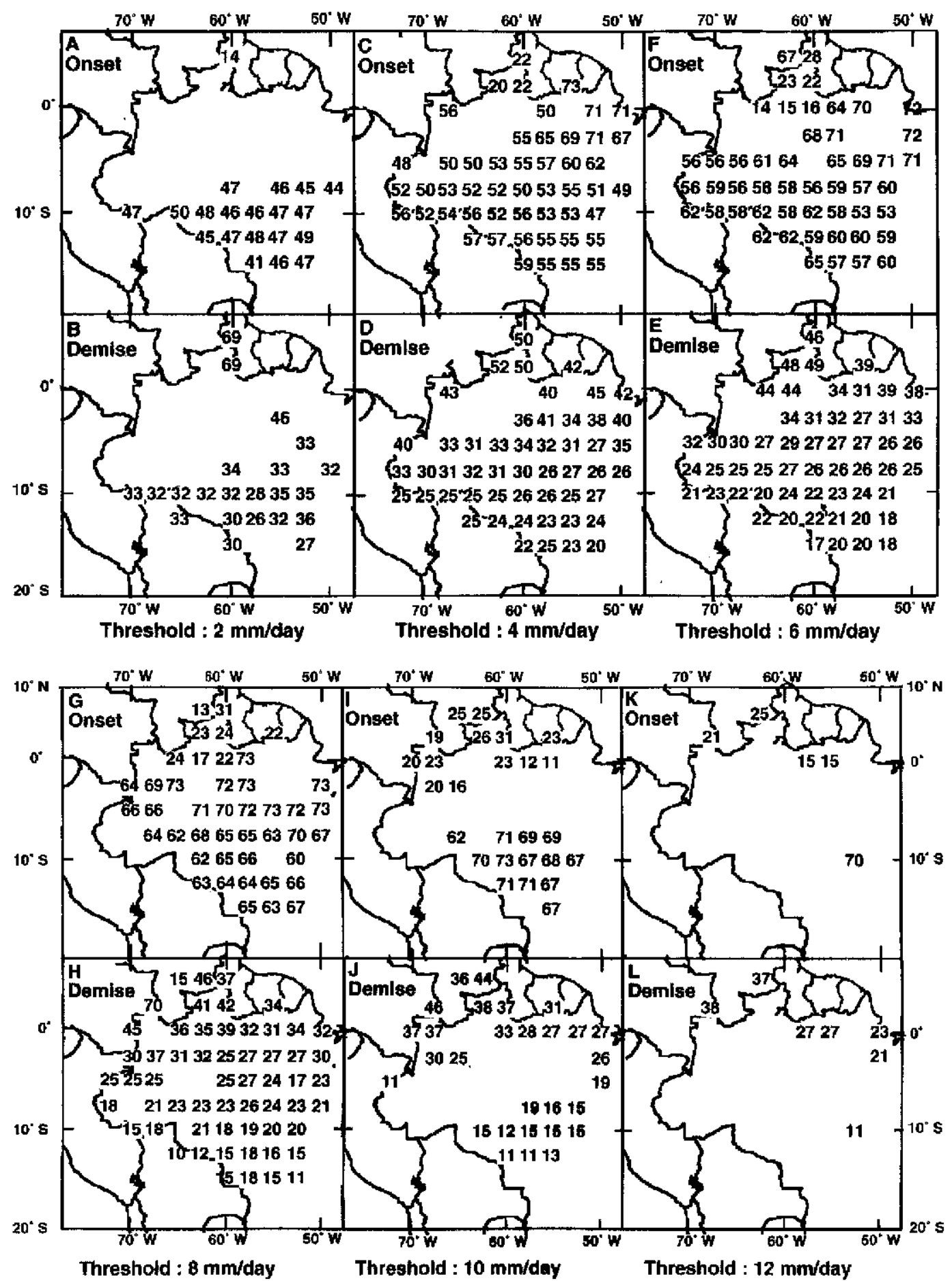

FIG. 5. As in Fig. 3 except that various thresholds are used to define onset, and values are plotted at each grid point where onset and end are defined. Onset and end of rainy season for threshold of (a), (b) $2 \mathrm{~mm} \mathrm{day}^{-1}$, (c), (d) $4 \mathrm{~mm} \mathrm{day}^{-1}$ (same as shown in Fig. 2), (e), (f) 6 mm day ${ }^{-1}$, (g), (h) $8 \mathrm{~mm} \mathrm{day}^{-1}$, (i), (j) $10 \mathrm{~mm} \mathrm{day}^{-1}$, (k), (1) $12 \mathrm{~mm} \mathrm{day}^{-1}$.

served in southern Amazon (Figs. 12d,e), compared to the central and northern regions. By looking at the onset and end dates, one can notice the difference in the timing of the onset and end between northern, central, and southern Amazon. Important features are the tendency for late onsets and early ends in central and mouth Amazon (Figs. 13c,d) during the El Niño years 1982/83 and $1991 / 92$, while a somewhat contrasting pattern is observed for the La Niña year 1988/89. The characteristics of rainfall variability in 1982/83 and 1988/89 were rep- 

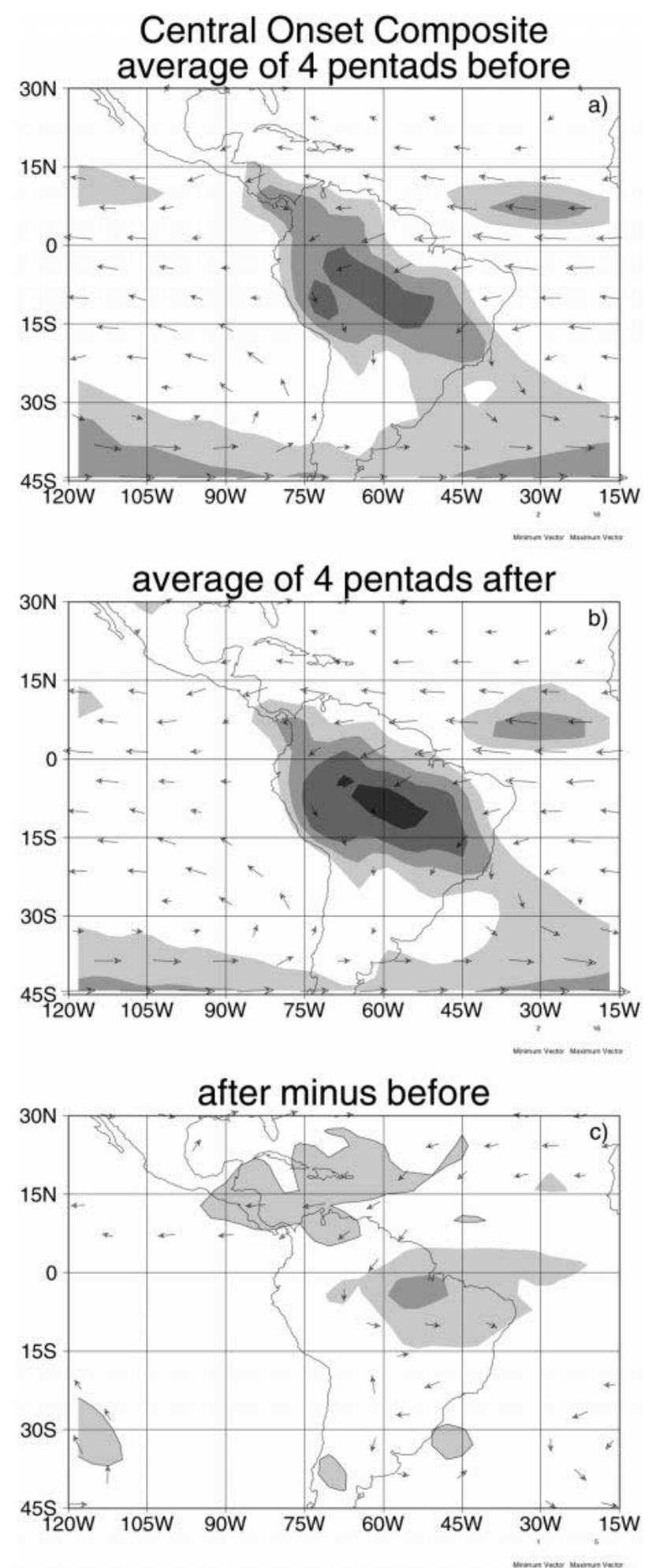

FIG. 6. Composites of $850-\mathrm{mb}$ vector wind and OLR for central Amazon. (a) Average of four pentads before onset (defined by rainfall); (b) average of four pentads after onset (not including pentad of onset). Vectors with speeds below $2 \mathrm{~m} \mathrm{~s}^{-1}$ are not plotted. Maximum vector length is at speed of $16 \mathrm{~m} \mathrm{~s}^{-1}$. (c) Difference of after (b) minus before (a). Minimum vector plotted is at speed of $1 \mathrm{~m} \mathrm{~s}^{-1}$. Maximum vector length is at speed of $5 \mathrm{~m} \mathrm{~s}^{-1}$. Shading begins at $10 \mathrm{~W} \mathrm{~m}^{-2}$ with an interval of $10 \mathrm{~W} \mathrm{~m}^{-2}$. Positive differences are also contoured. Circulation fields are from NCEP-NCAR reanalysis.
ECMWF Central Onset Composite average of 4 pentads before
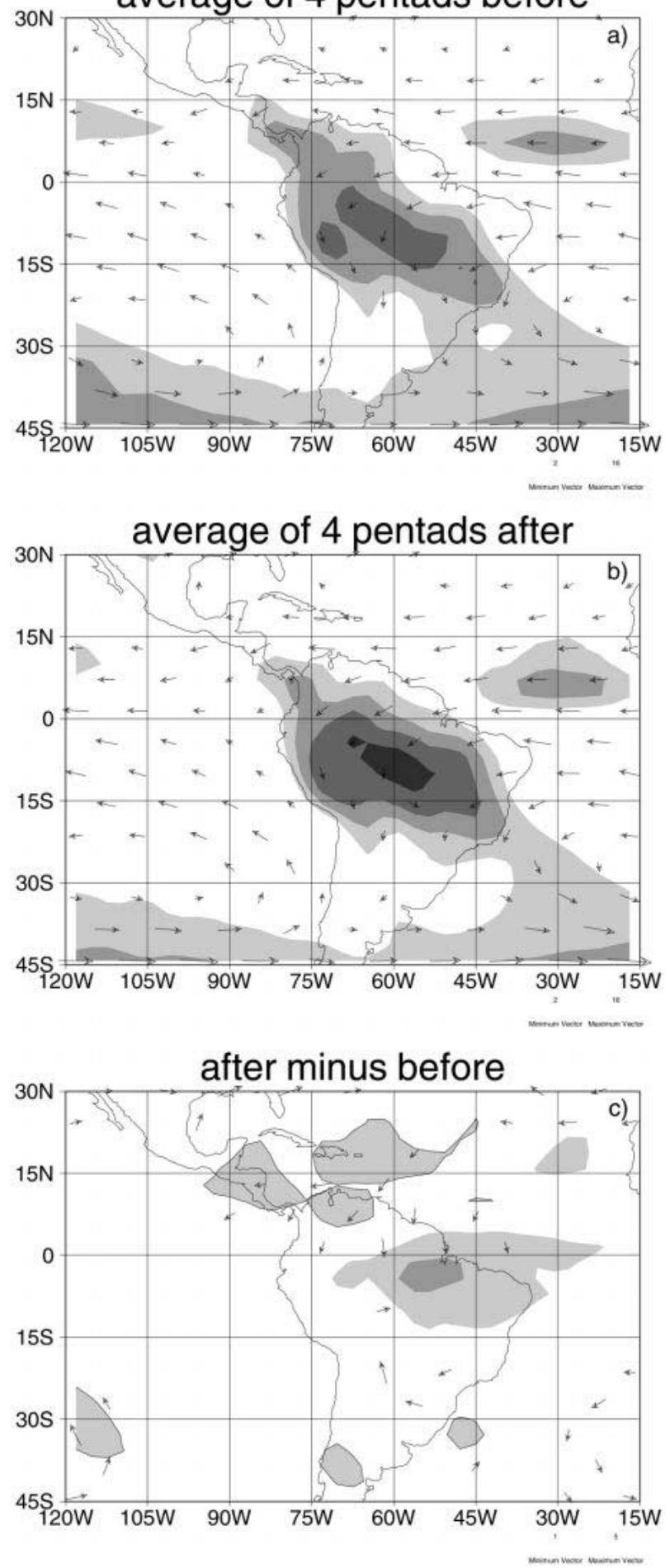

FIG. 7. As in Fig. 6 except that circulation fields are from ECMWF reanalysis. 


\section{Mouth of Amazon Onset Composite average of 4 pentads before}
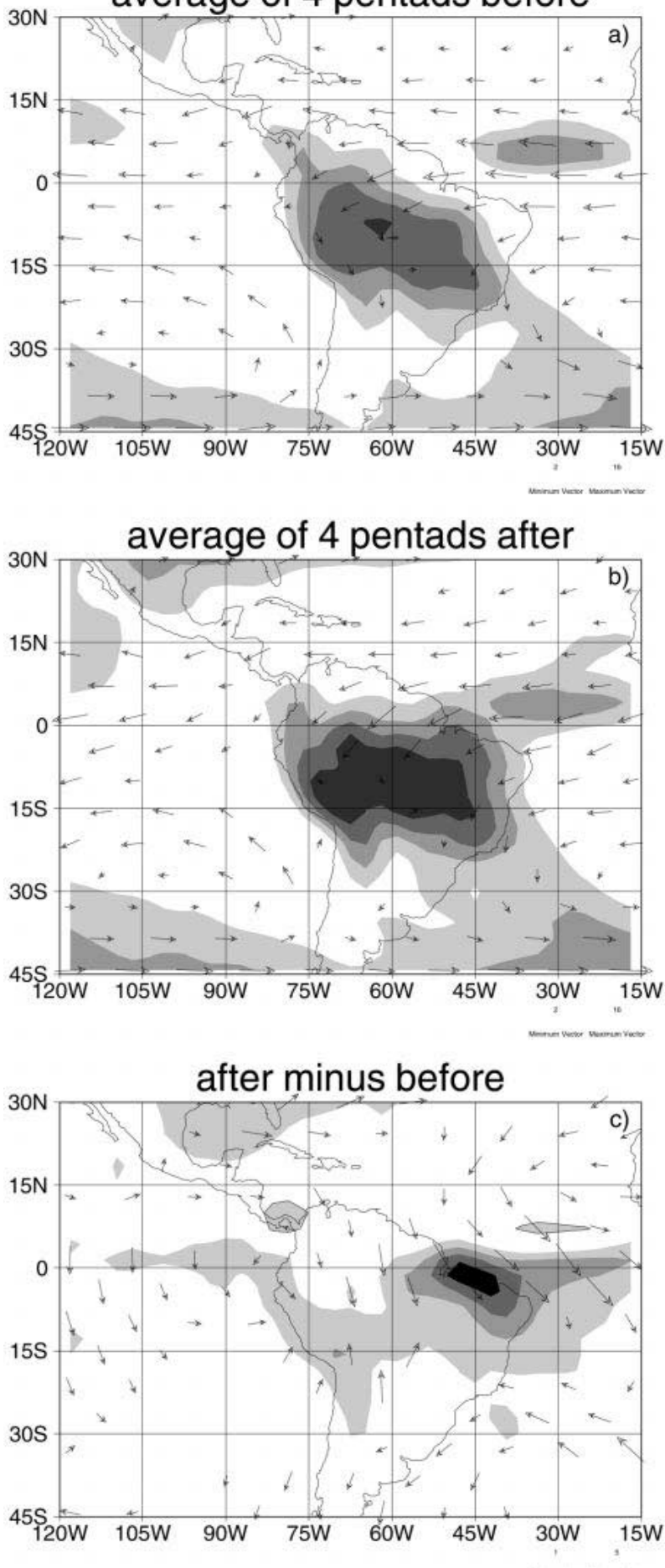

FIG. 8. As in Fig. 6 except for mouth of Amazon.
ECMWF Mouth of Amazon Onset Composite average of 4 pentads before
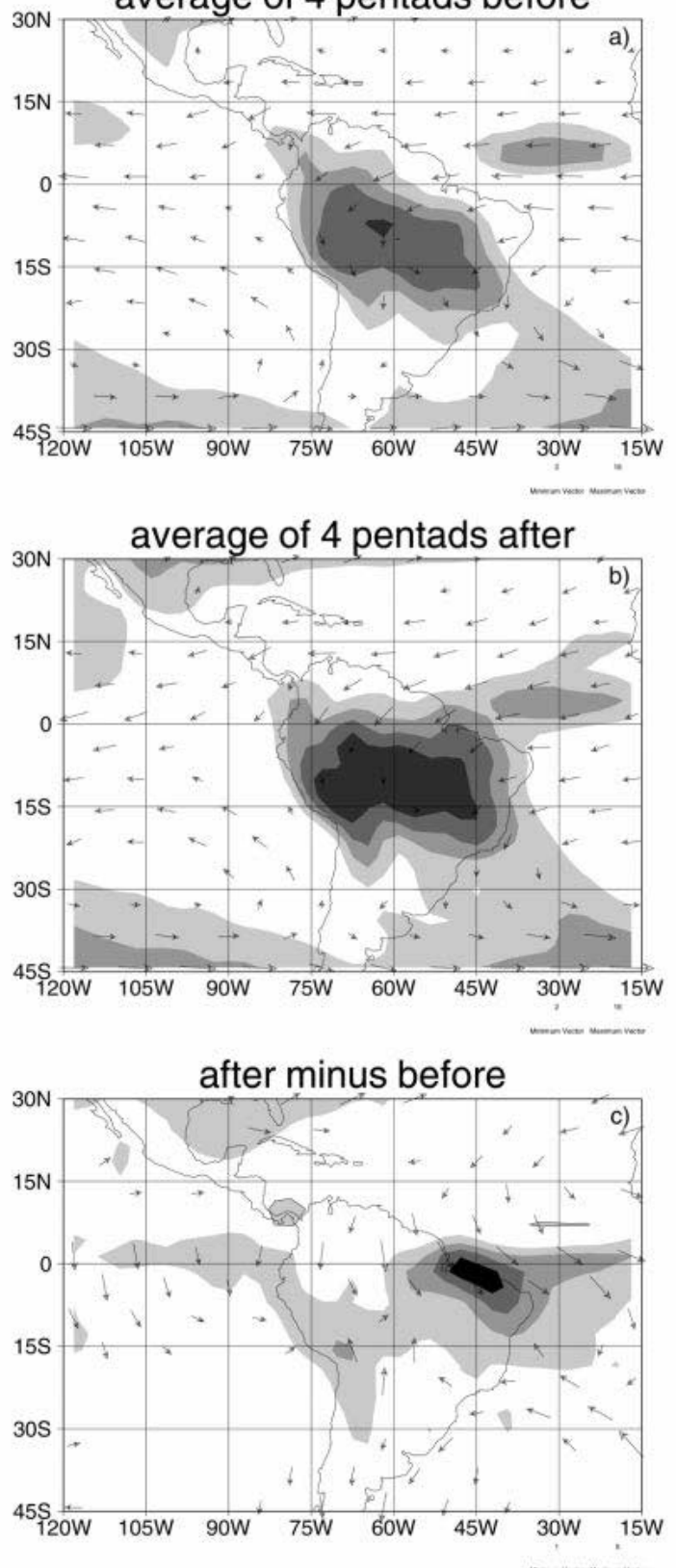

FIG. 9. As in Fig. 7 except for mouth of Amazon.

resentative of two intense extremes of the Southern Oscillation (SO), where the SST forcing was very strong. Given the lack of complete data it was not possible to study other intense extremes of the SO. However, we must keep in mind that the strongest impacts of El Niño in the Amazon Basin are mainly during an event characterized as very strong, such as in 1982/83 (Marengo 1992) or more recently in $1997 / 98$.

Somewhat surprisingly, in most regions (not including the northwest, where onset is rarely defined using 
Southeast Onset Composite average of 4 pentads before

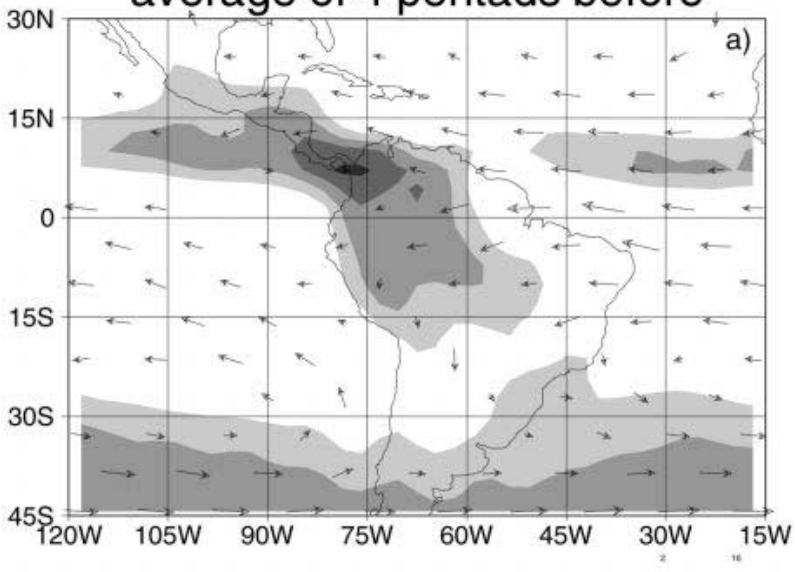

average of 4 pentads after



after minus before

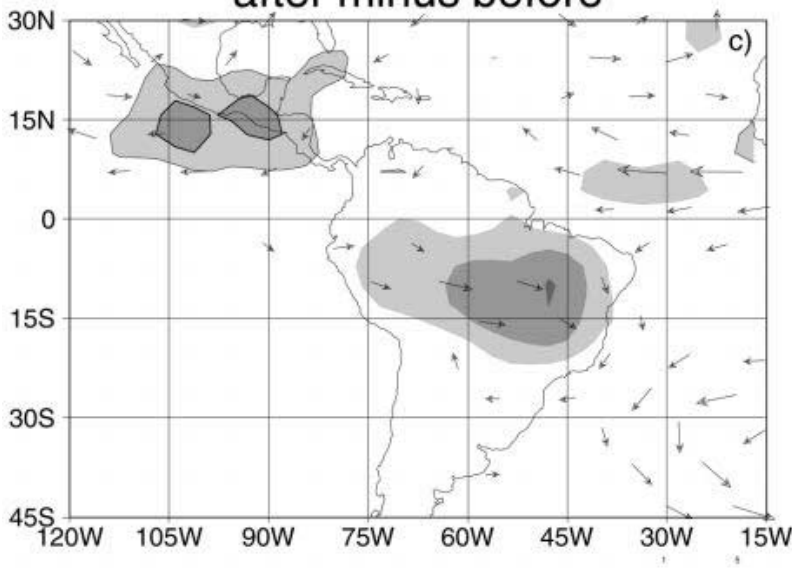

FIG. 10. As in Fig. 6 except for southeast Amazonia.
ECMWF Southeast Onset Composite average of 4 pentads before
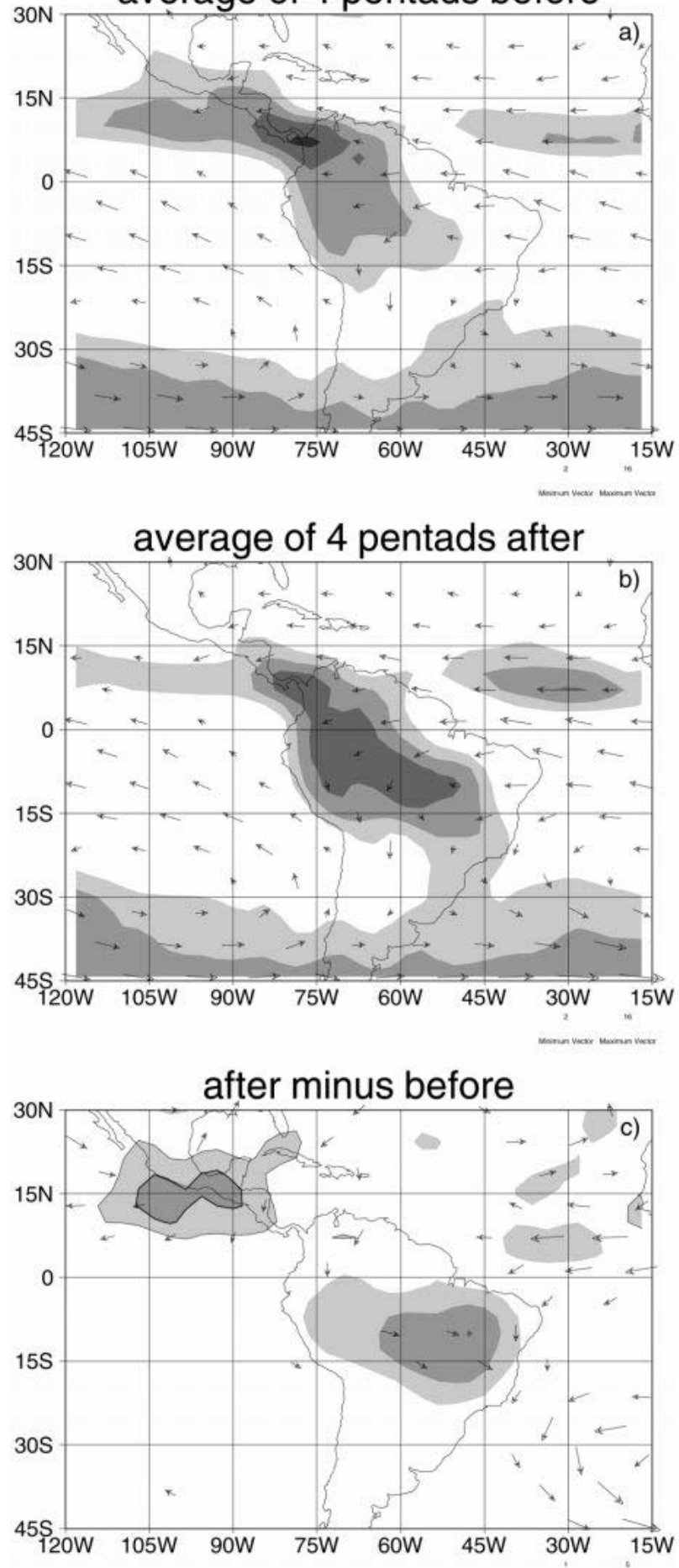

FIG. 11. As in Fig. 7 except for southeast Amazonia. 
the present definition) there is little correlation between the length of the rainy season and the total rainfall (defined as the amount of rainfall between onset and end on a year-to-year basis). In the central Amazon, the relationship between length and total is 0.5 , but in the other regions it is never above 0.35 . Similarly, there are only weak relationships between the onset or end and total accumulation, although always of the expected sign (e.g., a delayed onset is associated with low accumulation). In the central and northern Amazon there are moderate negative relationships (correlations of -0.55 and -0.40 ) between the dates of onset and end of the rainy season, and little linear relationship in the other three regions.

Figures 13a-f show the pentad time series of rainfall for two cases: the strong El Niño and La Niña events of 1982/83 and 1988/89. A larger variability of rainfall is observed in the northern as compared to the southern basin. For the two regions that apparently show the best associations between the extremes of the Southern Oscillation and the onset/end (central and mouth of the Amazon), Figs. 13c,d show a shorter rainy season in $1982 / 83$, with a late onset as compared to a longer rainy season with an early onset in 1988/89.

\section{c. Links between onset and end of the rainy season and SST}

The large-scale thermodynamic conditions ultimately control the onset of the rainy season in the tropical Amazon through a moistening of the PBL (e.g., Fu et al. 1999). About 50\% of Amazon rainfall come from moisture entering the Amazon air shed from horizontal advection (e.g., Brubaker et al. 1993). Therefore, since the rate of evaporation from the sea surface can be quite sensitive to SST, one may reasonably hypothesize that SST variations cause variations in the onset and end date of the rainy season.

In this section, maps are presented of the correlation between monthly averages of SST and the pentad of onset and end of the rainy season. There are $18 \mathrm{yr}$ of data, but in some locations (excluding the northwest, where onset and end are almost never defined) the onset or end criteria are not met in as many as three of those years. A value of \pm 0.5 is conservatively estimated to be statistically relevant at the 5\% level using a twosided $t$ test.

\section{1) Central Amazon}

The average onset date in the central Amazon is the pentad centered on 25 September, with a range from the pentad centered on 16 August to that centered on 19 December. Figure 14a shows the correlation between central Amazon onset and August SST. In the eastern south equatorial Atlantic, there is an area of negative correlation, indicating that a delayed onset is associated with anomalously cool SST. The Atlantic pattern is quite similar in September, but shrinks in magnitude and size in the bracketing months (not shown).

In the Pacific there is a pattern of equal magnitude, but of opposite sign, which is centered just north of the equator east of about $150^{\circ} \mathrm{W}$. The Pacific pattern, however, is not confined to August and September, but is evident in a similar configuration from April to December. The relative persistence of the correlation in the Pacific, extending to months whose influence would not be expected to affect onset, is presumably due to a large autocorrelation of SST there owing to the presence of El Niño/La Niña. The exclusion of 1982, 1984, or 1991, the years with large anomalies in onset date, does not qualitatively change the figure.

The belief that the observed pattern of correlations is real is bolstered by its physical plausibility. If one accepts that deep convection moves in its annual cycle along a northwest to southeast path (e.g., Horel et al. 1989), then it is believable that warm SSTs in the mean position of the eastern Pacific ITCZ, where convection is established in northern summer until it moves southeastward into the Amazon, and cold SSTs south of the equator in the Atlantic, where they likely slow the buildup of PBL moisture that is associated with the onset of convection (e.g., Fu et al. 1999), would delay the annual transition of convection into the Southern Hemisphere. This scenario is consistent with the results of Joseph et al. (1991) and that implied by Meehl (1987), whereby cold SST near Australia results in a delayed onset of the monsoon on that continent.

The end date of the central Amazon rainy season is the pentad centered on 7 June, with a range between the pentad centered on 13 May and that centered on 12 July. The correlation map for May is shown in Fig. 14b. In June and July (not shown) the pattern is confined closer to the coast of South America. The positive correlations indicate that a late withdrawal is associated with warm Atlantic SSTs, again physically plausible. For the withdrawal, however, there is no indication of anomalous SSTs in the Pacific.

\section{2) Mouth of the Amazon}

Onset of the rainy season near the mouth of the Amazon always occurs after the rainy season has been established in the central Amazon, but there is little correlation between the dates of onset. The average pentad of onset near the Amazon mouth is centered on 4 December, with the earliest and latest pentads of onset centered on 4 November and 24 December. The largest extent of relevant correlations between SST and onset near the Amazon mouth is in September in the eastern Pacific, south of the equator (Fig. 15a), but the central part of the pattern is evident from August to December (not shown). This pattern is difficult to interpret both because maximum correlations do not occur in the month preceding onset and because SSTs south of the equator in the eastern Pacific are cool with clear air 


\section{Interannual variability of the rainy season in Amazonia}

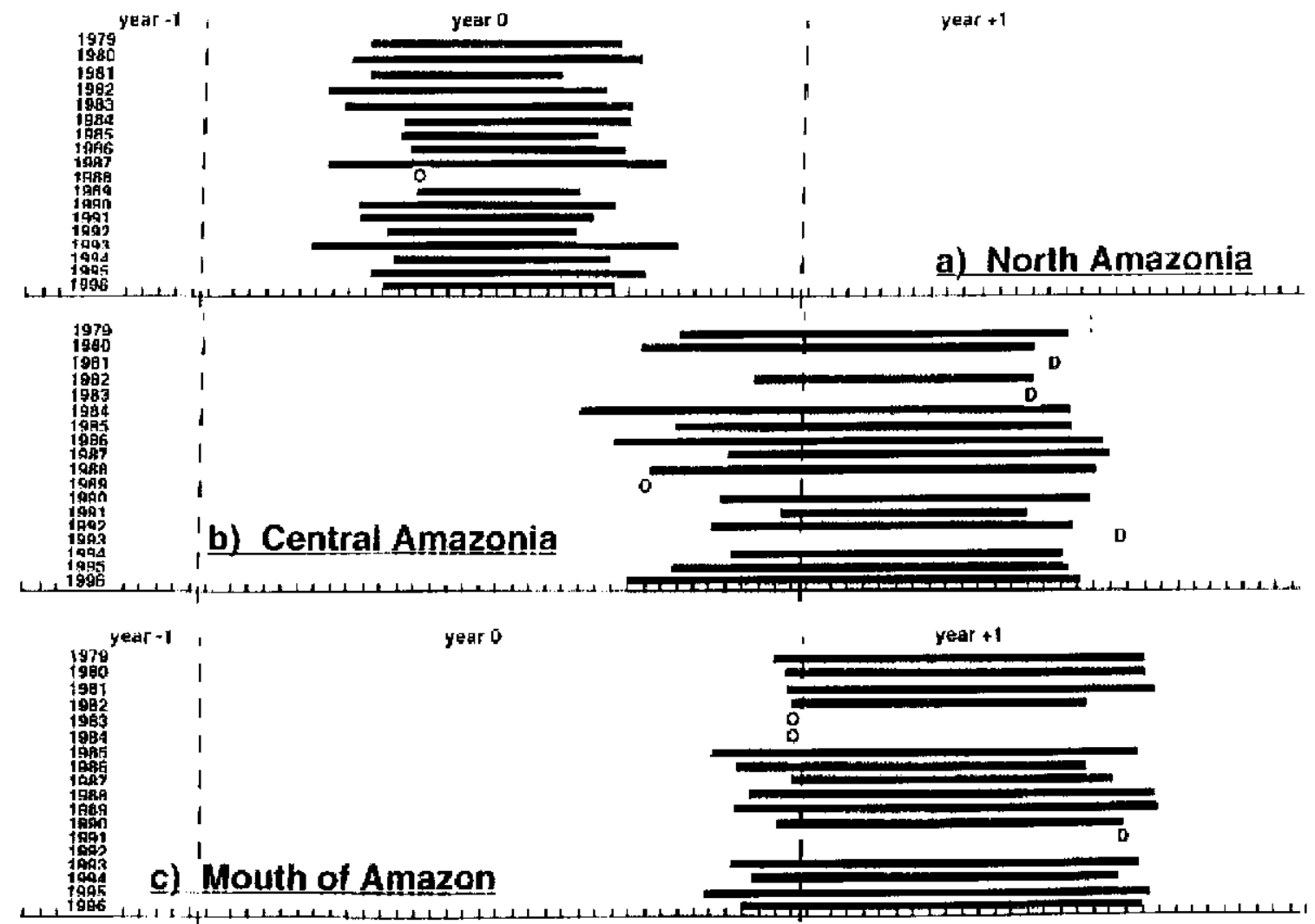

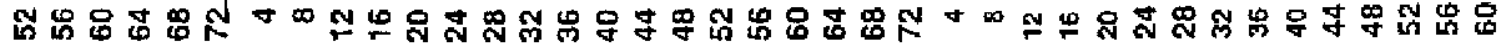

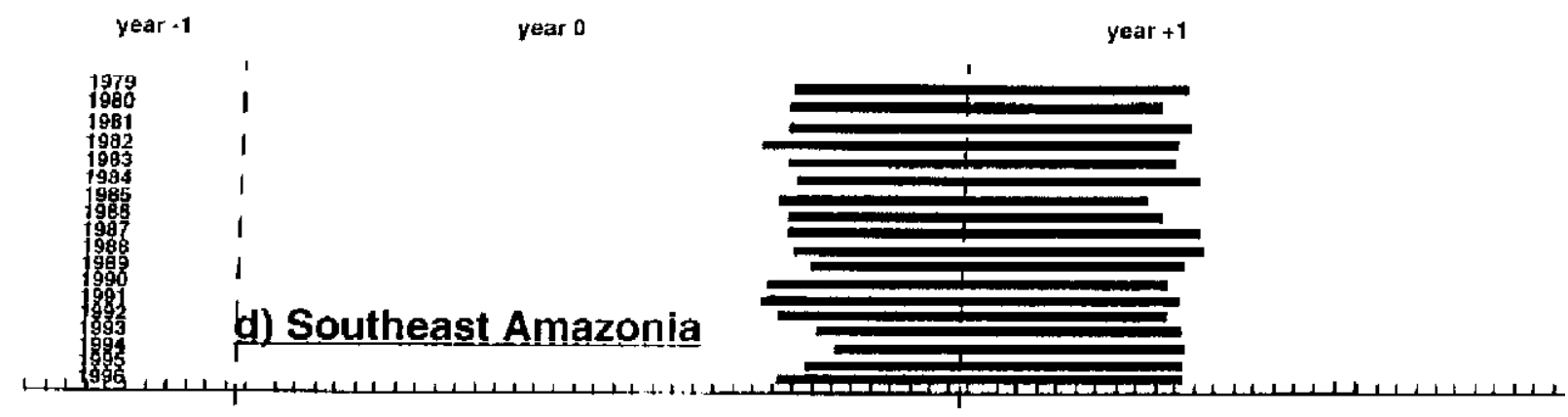

e) Southwest Amazonia

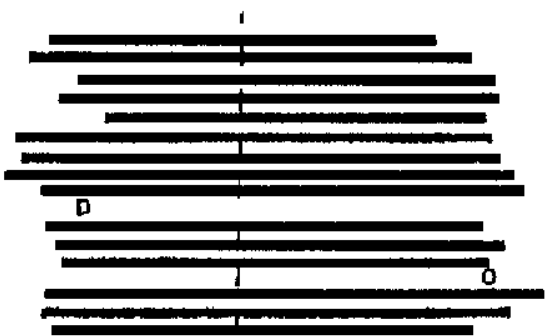

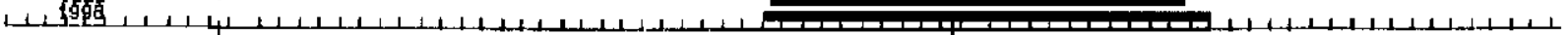

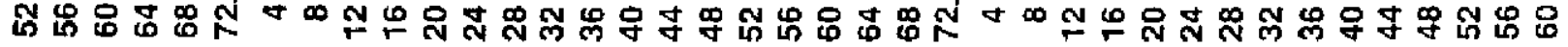



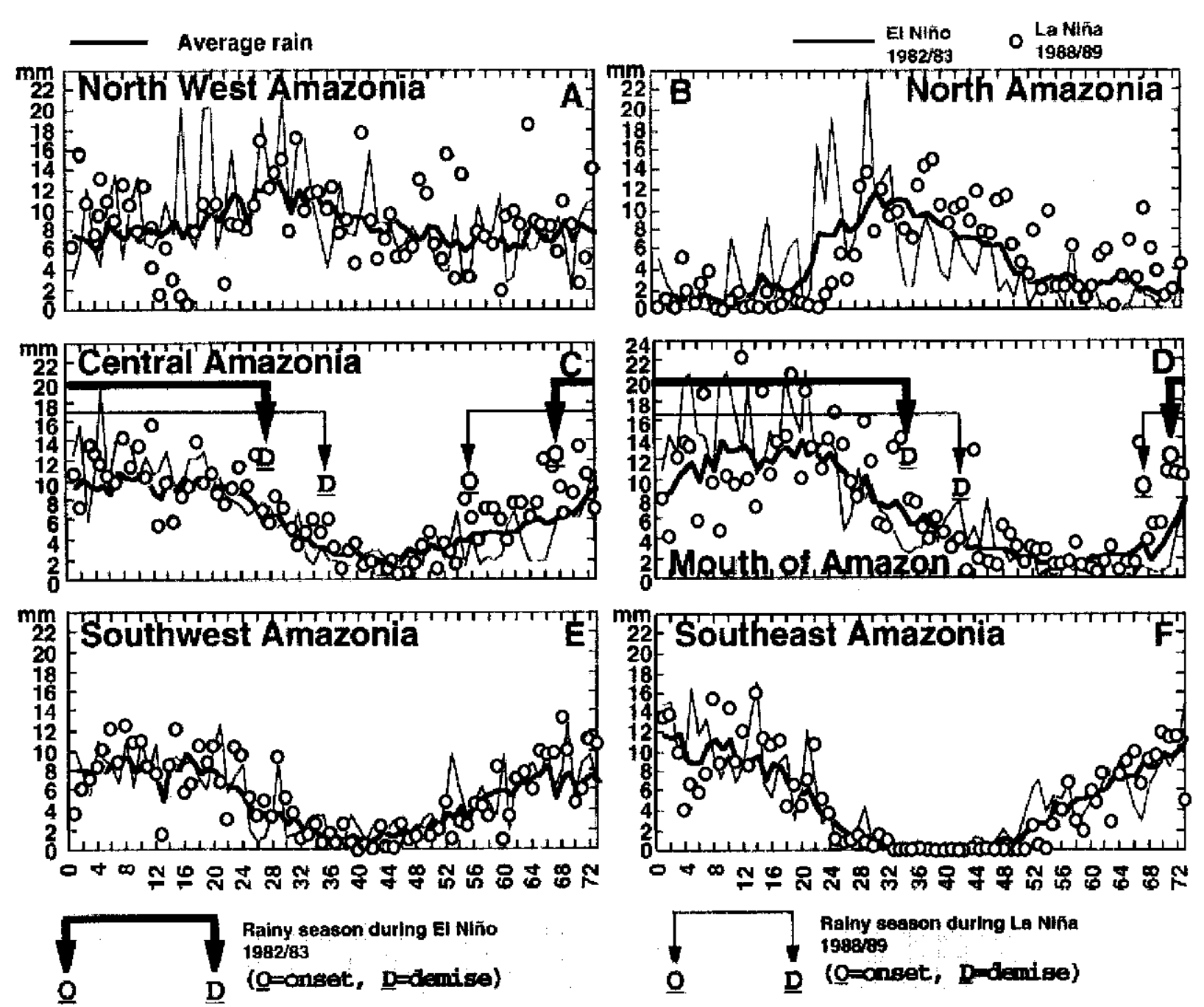

FIG. 13. Pentad rain in Amazonia during two extremes of the Southern Oscillation: El Niño 1982/83 (thin line), La Niña $1988 / 89$ (circles). Average is indicated by a thick line. (a) Northwest, (b) north, (c) central, (d) mouth, (e) southwest, (f) southeast. (c, d) Arrows indicate the onset (O), end (D), and extension of the rainy season, for the El Niño 1982/83 (thick line) and La Niña 1988/89 (thin line).

above, so changes there should not cause circulation changes via changes in convection. One possibility for a stronger correlation between SST in September and the onset of the rainy season in this region is that the coldest SST in the southeastern Pacific usually occurs in September. Hence, the fluctuations of SST there in September could have more contribution to the correlation.

It is surprising that there are no relevant correlations in the Atlantic, given the proximity of the mouth to that ocean. However, the meridional SST gradient, together with the meridional sea level pressure gradient, seems to be more important for the onset of the rainy season, rather than the magnitude of the SST in the Atlantic Ocean (Marengo 1992).

The end date near the Amazon mouth is best correlated with SST during the months of September to March prior to the end date (the correlation with February SST is shown in Fig. 15b), even though the average end date is not until the pentad centered on 17

FIG. 12. Interannual variability of the rainy season in Amazonia for regions with defined rainy season: (a) north, (b) central, (c) mouth, (d) southeast, (e) southwest. Bars represent the rainy season, the extreme left side represents the pentad of onset, and the extreme right side represents the pentad of the demise. For (a) onset and demise are on the same year, while for the other four regions (b)-(e) the onset is on one year (year 0) and the demise is on the year after (year 1). In some regions and years, O indicates that only the onset was defined, and $\mathrm{D}$ indicate that only the demise was defined, mainly due to lack of rainfall data. 


\section{Central Amazon Onset Date Versus August SST}

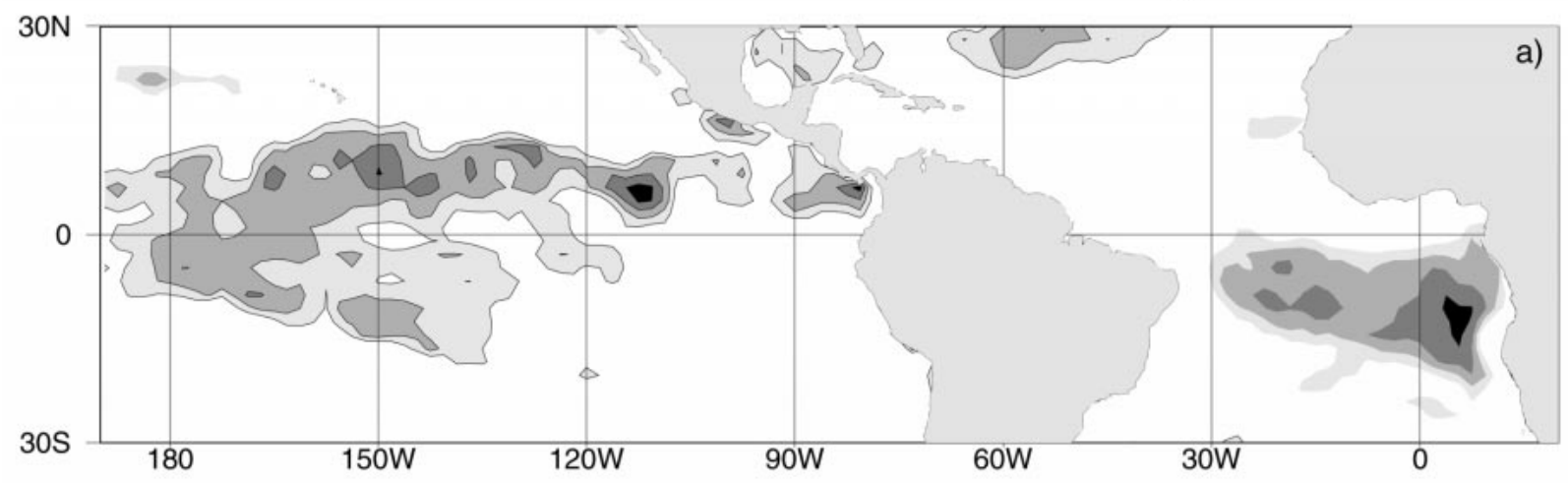

Central Amazon End Date Versus May SST

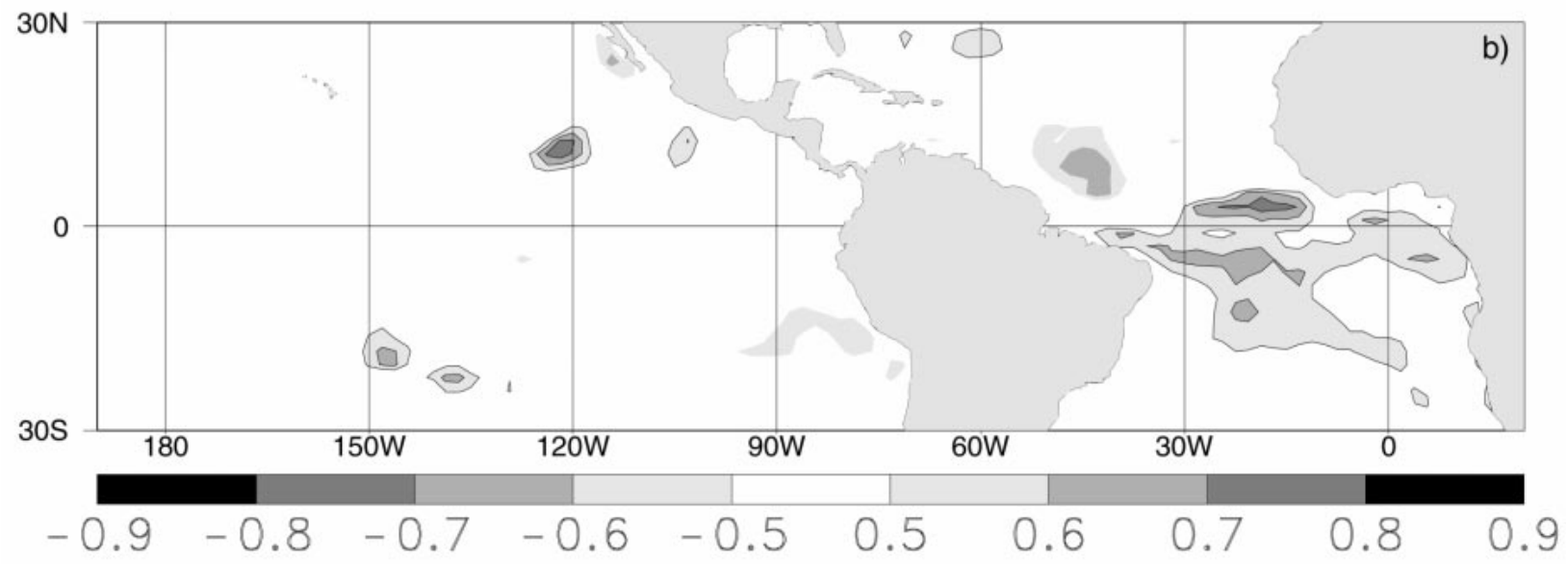

FIG. 14. Correlation between (a) pentad of onset of central Amazon rainy season and Aug SST and (b) pentad of end of central Amazon rainy season and May SST. Shading starts at 0.5 , with an interval of 0.1. Positive correlations are contoured.

July and the earliest recorded withdrawal date is the pentad centered on 22 June. The negative correlations in the Pacific south of the equator, however, remain well correlated with the end date through May.

Thus, as in central Amazon, a warm Pacific seems to be associated with a late onset and an early withdrawal. The cases shown in Figs. 13c,d associated with the largest anomalies of the SO index during the period of study are consistent with these findings, although correlations that exclude these extreme years (not shown) are quite similar.

\section{3) Northern Amazon}

The rainy season in the northern Amazon is, on average, almost exactly out of phase with that in the southeast, although the variability of the two is not well correlated. The average onset of the northern Amazon rainy season is on 17 April with a range from 4 March to 3 May. Its average ending date of 5 September (with extremes of 1 August and 15 October) is about 20 days before onset in the central Amazon. The onset correlation map with April (Fig. 16) shows negative correlation in the equatorial Pacific and positive correlation in the central equatorial Atlantic. The correlations in the Atlantic are actually largest in January, but centered at about $15^{\circ} \mathrm{S}$, while those in the Pacific remain along the equator, but grow until June. This pattern observed in April is consistent with, but opposite to, the pattern associated with onset in the central Amazon. In the case of onset in the north, warm Atlantic SST and cold Pacific seem to conspire to delay the transition of convection from the Southern into the Northern Hemisphere. It should be noted, however, that onset in the northern Amazon, although north of the equator, occurs before transition from the 


\section{Mouth of Amazon Onset Date Versus September SST}

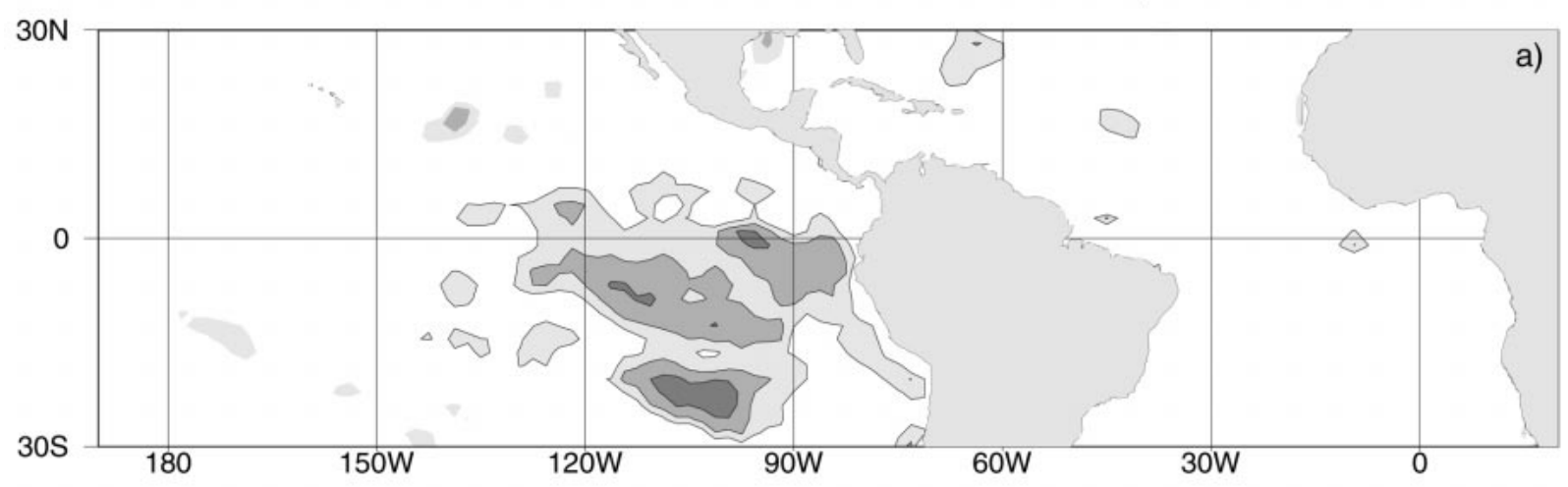

\section{Mouth of Amazon End Date Versus February SST}

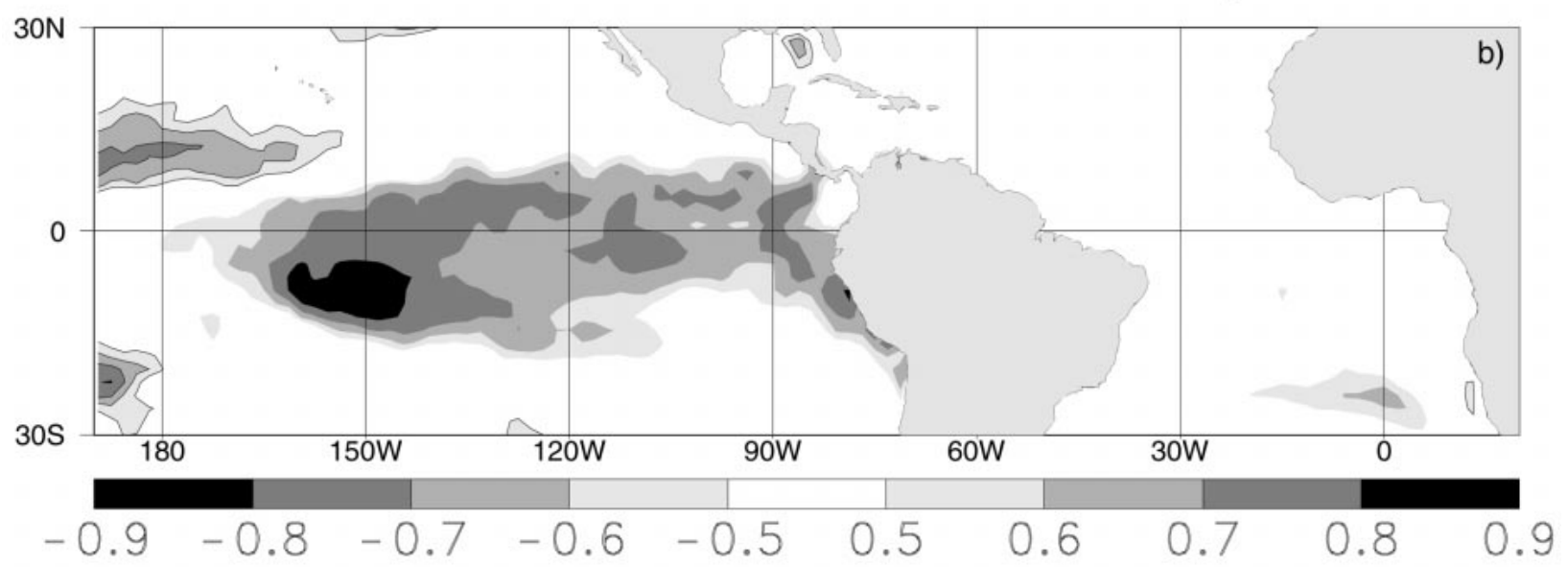

FIG. 15. As in Fig. 14 except for mouth of Amazon. (a) Onset with Sep SST. (b) End with Feb SST.

Southern into the Northern Hemisphere as determined by Horel et al. (1989). The correlations between SST and end date are generally small and are not shown.

\section{4) Southern AMAZON}

There is no apparent relation to the onset or end date in the southwest or southeast to SST. This is consistent with the results of $\mathrm{Fu}$ et al. (1999), who found that in the southern Amazon, convection is more closely related to the warm surface temperature than near the equator, where the best association is with humidity in the PBL.

\section{Summary and discussion}

The onset date of the rainy season in the Brazilian Amazon Basin has been documented using rainfall data from many stations. Stations were averaged into pentads on both a grid and in individual regions, representative of the differing climate regimes within the Amazon. Onset is defined as the pentad that rainfall exceeds a given threshold, provided that average rainfall was lower in the preceding onset, and higher in pentads after onset. The end of the rainy season was defined in a similar manner, but for rainfall below a certain threshold. For the threshold used here, neither onset nor end is defined in the northwest Amazon, because rainfall is almost always above the chosen threshold.

The average onset agrees qualitatively with onset defined from OLR in this study and in Kousky (1988). In general, onset progresses toward the southeast, arriving in mid-October, and then toward the mouth of the Amazon, arriving near the end of the year. The end dates are earliest in the southeast and progress to the north, but the withdrawal is slower than onset.

The onset dates, however, are quite sensitive to chang- 


\section{Northern Amazon Onset Date Versus April SST}

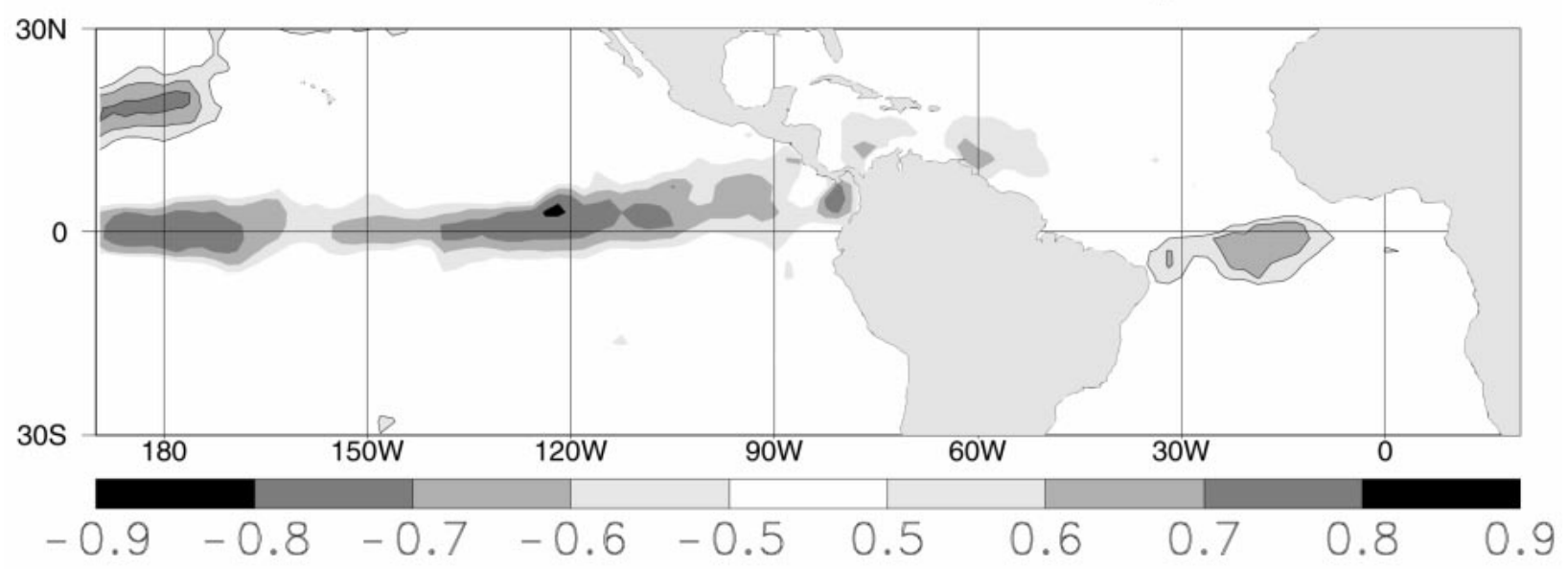

FIG. 16. As in Fig. 14 except for northern Amazon with Apr SST.

es in the threshold. If the threshold is doubled, for example, the sense of onset is reversed, with onset occurring toward the northwest. Changes in threshold do not change the direction of the progression of the end of the rainy season.

Composites of OLR and the low-level wind field show that in central Amazonia north of the equator, onset is associated with an anomalous anticyclone and enhanced trade winds in the Atlantic. Near the mouth of the Amazon, however, onset is associated with largescale northerly anomalies, and the zonal component of the trade winds is reduced.

The central Amazon shows the largest variation in the date of onset. In several years, onset in the southeast occurs before that in the central Amazon, but onset near the mouth is always latest. The withdrawal is more regular than onset, with the end in central Amazonia always later than that in the southeast.

There is an unexpectedly low relationship between the length of the rainy season and total accumulation, as seasonal rainfall anomalies do not show a correlation with the date of onset, nor is it possible to assume that a late onset will determine a dry year. This means that there must be a change in the distribution of rainfall (e.g., a difference in the percentage of days without rainfall) from wet to dry years. This topic will be investigated in another study. Likewise, there is little relationship between the onset (and end) date and the total accumulation. This is unfortunate because if there were, onset date would be an easy way to predict rainfall totals.

There is an apparent association between SST anomalies in the tropical Atlantic and Pacific and the onset and end dates in parts of the Amazon. Maps of the correlation between SST and the pentads of onset and central and near the mouth of the Amazon reveal large areas with relevant correlations. Negative anomalies in the Atlantic and positive anomalies in the Pacific are associated with a delayed onset, which is consistent with the notion that anomalies in this configuration should act to delay the seasonal migration of intense convection from the Northern into the Southern Hemisphere. A delayed withdrawal is associated with warm anomalies in the Atlantic. A delayed onset in the northern Amazon, whose rainy season begins on average a few pentads earlier than the end in the Amazon south of the equator, is associated with a warm Atlantic and cold Pacific. At the mouth of the Amazon, a delayed onset occurs when SST is warm in the eastern Pacific south of the equator, and the end is delayed when eastern equatorial Pacific SSTs are cold. In the southern Amazon, there is little association between variations in onset and end of the rainy season and those in SST. Thus, the mechanism proposed by Fu et al. (1999), who found that land surface heating here has more influence on onset dates than do SST variations in the adjacent tropical oceans, is apparently valid.

The general consistency and physical plausibility of the correlation maps gives one confidence that the observed patterns truly are associated with anomalies in the onset and end of the rainy season. The correlations are always of the sign that a warm Pacific favors a short season in the Southern Hemisphere Amazon, and a warm Atlantic favors a long season. On the other hand, there are several reasons to be skeptical of the correlation patterns. It is suspicious that patterns in the Pacific are sometimes largest well before or after the months one would expect SST to have an influence on the onset or end of the rainy season. This is undoubtedly due to the large persistence of SST in the eastern equatorial Pacific. Also, the large spatial coherence of SST means that although large areas appear to be statistically relevant, one may be misled by the relatively few degrees of spatial freedom (e.g., Livezey and Chen 1983). Finally, one must wonder why SST anomalies in the eastern Pacific south of the equator, in a region of little 
convection, should be associated with onset near the mouth of the Amazon. While interesting, definite conclusions about the results had best await the test of time.

Acknowledgments. Jose A. Marengo was supported by the Brazilian Conselho Nacional de Desenvolvimiento Cientifico e Tecnologico $(\mathrm{CNPq})$, and Brant Liebmann was partly supported by a grant from the Pan American Climate Studies Program of the NOAA Climate and Global Change Program (GC96-946). The authors wish to thank the Inter American Institute for Global Change (IAI-ISP1) for providing partial funding for this research. Publication of this paper was possible throughout a grant from the Fundacao de Amparo a Pesquisa do Estado de São Paulo (FAPESP).

\section{REFERENCES}

Aceituno, P., 1988: On the functioning of the Southern Oscillation in the South American sector. Part I. Mon. Wea. Rev., 116, 505524.

Brubaker, K. L., D. Entekhabi, and P. S. Eagleson, 1993: Estimation of continental precipitation recycling. J. Climate, 6, 1077-1089.

Davidson, N. E., J. L. McBride, and B. J. McAvaney, 1983: The onset of the Australian monsoon during winter MONEX: Synoptic aspects. Mon. Wea. Rev., 111, 496-516.

,-- , and -1984 : Divergent circulations during the onset of the 1978-79 Australian monsoon. Mon. Wea. Rev., 112, 16841696.

Figueroa, S. N., and C. Nobre, 1990: Precipitation distribution over central and western tropical South America. Climanalise, 5, 3644.

Fu, R., B. Zhu, and R. Dickinson, 1999: How do the atmosphere and land surface influence the seasonal changes of convection in tropical Amazon? J. Climate, 12, 1306-1321.

Garreaud, R., 1999: Multiscale analysis of the summertime precipitation over the central Andes. Mon. Wea. Rev., 127, 901-921.

- and J. M. Wallace, 1998: Summertime incursions of midlatitude air into subtropical and tropical South America. Mon. Wea. Rev. 126, 2713-2733.

Hastenrath, S., 1997: Annual cycle of upper air circulation and convective activity over the tropical Americas. J. Geophys. Res. 102, 4267-4274.

— Brazil. Quart. J. Roy. Meteor. Soc., 102, 77-92.

Hendon, H., and B. Liebmann, 1990: A composite study of onset of the Australian summer monsoon. J. Atmos. Sci., 47, 2227-2240.

Holland, G. J., 1986: Interannual variability of the Australian monsoon at Darwin. Mon. Wea. Rev., 114, 594-604.

Horel, J. D., A. N. Hahmann, and J. E. Geisler, 1989: An investigation of the annual cycle of convective activity over the tropical Americas. J. Climate, 2, 1388-1403.

Joseph, P. V., B. Liebmann, and H. H. Hendon, 1991: Interannual variability of the Australian summer monsoon onset: Possible influence of Indian summer monsoon and El Niño. J. Climate, 5, 529-538.

Kalnay, E., and Coauthors, 1996: The NCEP-NCAR 40-Year Reanalyses Project. Bull. Amer. Meteor. Soc., 77, 437-471.

Kiladis, G. N., and H. F. Diaz, 1989: Global climatic anomalies associated with extremes in the Southern Oscillation. J. Climate, 2, 1069-1090.

Kousky, V. E., 1988: Pentad outgoing longwave radiation climatology for the South American sector. Rev. Bras. Meteor., 3, 217-231.

Lau, N.-G., 1997: Interactions between global SST anomalies and the midlatitude atmospheric circulation. Bull. Amer. Meteor. Soc., 78, 21-34 and M. J. Nath, 1994: A modelling study of the relative roles on tropical and extratropical SST anomalies in the variability of the global atmosphere-ocean system. J. Climate, 7, 1184-1207.

Lenters, J., and K. Cook, 1995: Simulation and diagnosis of the regional summertime precipitation climatology of South America. J. Climate, 8, 2298-3005.

Liebmann, B., and C. A. Smith, 1996: Description of complete (interpolated) outgoing longwave radiation data set. Bull. Amer. Meteor. Soc., 77, 1275-1277.

, J. A. Marengo, J. D. Glick, V. E. Kousky, I. C. Wainer, and O. Massambani, 1998: A comparison of rainfall, outgoing longwave radiation and divergence over the Amazon Basin. J. Climate, 11, 2898-2909.

Livezey, R. E., and W. Y. Chen, 1983: Statistical field significance and its determination by Monte Carlo techniques. Mon. Wea. Rev., 111, 46-59.

Marengo, J., 1992: Interannual variability of surface climate in the Amazon basin. Int. J. Climatol., 12, 853-863.

_ 1995: Deep convection over the tropical South American sector as deduced from the ISCCP-C2 data. Int. J. Climatol., 15, 9951010 .

_ - J. Tomasella, and C. Uvo, 1998: Long-term streamflow and rainfall fluctuations in tropical South America: Amazonia, Eastern Brazil and Northwest Peru. J. Geophys. Res., 103, 17751783.

Meehl, G. A., 1987: The annual cycle and interannual variability in the tropical Pacific and Indian Ocean regions. Mon. Wea. Rev., 115, 27-50.

Moura, A. D., and J. Shukla, 1981: On the dynamic of droughts in northeast Brazil: Observations, theory and numerical experiments with a general circulation model. J. Atmos. Sci., 38, 2653 2674.

Murakami, T., and A. Sumi, 1982: Southern Hemisphere summer monsoon circulation during 1978-79 WMONEX. Part I: Onset, active and break monsoon. J. Meteor. Soc. Japan, 60, 649-671.

Nicholls, N., J. L. McBride, and R. J. Ormerod, 1982: On predicting the onset of the Australian wet season at Darwin. Mon. Wea. Rev., 110, 14-17.

Nobre, P., and J. Shukla, 1996: Variations of sea surface temperature, wind stress and rainfall over the tropical Atlantic and South America. J. Climate, 9, 2464-2479.

Palmer, T., C. Brankovic, P. Viterbo, and M. J. Miller, 1992: Modeling interannual variations of summer monsoons. J. Climate, 5, 399417.

Ramage, C. S., 1971: Monsoon Meteorology. Academic Press, 296 pp.

Rao, G. V., and S. Erdogan, 1989: The atmospheric heat source over the Bolivian Plateau for a mean January. Bound.-Layer Meteor., 46, 13-33.

, and K. Hada, 1990: Characteristics of rainfall over Brazil Annual variations and connections with the Southern Oscillation. Theor. Appl. Climatol., 42, 81-91.

_ I. Cavalcanti, and K. Hada, 1996: Annual variations of rainfall over Brazil and water vapor characteristics of South America. J. Geophys. Res., 101, 36 350-26 551.

Reynolds, R., and T. Smith, 1994: Improved global sea surface temperature analysis. J. Climate, 7, 929-948

Rogers, J. C., 1988: Precipitation variability over the Caribbean and tropical Americas associated with the Southern Oscillation. J. Climate, 1, 172-182.

Ropelewski, C., and M. Halpert, 1987: Global and regional scale precipitation patterns associated with the El Niño/Southern Oscillation. Mon. Wea. Rev., 115, 1606-1626.

- and M. Halpert, 1989: Precipitation patterns associated with the high index phase of the Southern Oscillation. J. Climate, 2, 268-282.

Sugahara, S., 1991: Flutuaçoes interanuais, sazonais e inatrasazonais da precipitação no estado de São Paulo. Ph.D. thesis, Universidade de São Paulo, 140 pp. [Available from DCA/IAG, Uni- 
versity of São Paulo, Rua de Matao 1226, CEP 05508-900, SP, Brazil.]

Trenbeth, K., and J. G. Olson, 1988: ECMWF global analyses 197986; Circulation statistics and data evaluation. Tech. Note NCARTN-3OO + STR, 94 pp.

Troup, A. J., 1961: Variations in upper tropospheric flow associated with the onset of the Australian monsoon. Indian J. Meteor. Geophys., 12, 217-230.

Uvo, C. B., 1998: Influence of sea surface temperature on rainfall and runoff in northeastern South America: Analysis and mod- eling. Report 1021, Dept. of Water Resources Engineering, Lund University, 73 pp. [Available from Department of Resources Engineering, Lund University, S-22100 Lund, Sweden.]

Virmani, S. M., 1975: The agricultural climate of the Hyderabad regions in relation to crop planning. Internal Report, Farming Systems Program. ICRISAT, Hyderabat, India, 22 pp. [Available from Department of Meteorology, The Florida State University, Tallahassee, FL 32304.]

Zhou, J., and K.-M. Lau, 1998: Does a monsoon climate exist over South America? J. Climate, 11, 1020-1040. 